\title{
A CFD Analysis on the Influence of Upstream Surface Geometry Modifications of Clerestory Shaped Rib on Heat Transfer Characteristics of Solar Air Heater
}

\author{
D.V. Fernandes and Manjunath M.S.* \\ Department of Mechanical and Manufacturing Engineering, Manipal Institute of Technology, Manipal Academy of Higher Education, \\ Manipal, Karnataka, India-576104 \\ Phone: +917892346011
}

\begin{abstract}
Two-dimensional numerical analysis is conducted to determine the influence of upstream surface modifications of a novel clerestory shaped rib turbulator on thermal performance augmentation. The upstream surface of the rib is divided into two parts where the upper rib surface is always normal to the incoming flow and the lower rib surface, which is inclined to the flow. The elevation of the vertical surface is varied using non-dimensional approach length $(\mathrm{h} / \mathrm{e}=0,0.25,0.5$ and 0.75$)$, and the inclination of the lower surface is varied using the rib angle $\left(\theta=15^{\circ}, 45^{\circ}\right.$ and $90^{\circ}$ ). The relative roughness height and pitch of rib is fixed as 0.0421 and 12.5 , respectively. RNG $\mathrm{k}-\epsilon$ turbulence model is used in the analysis, and Reynolds number is varied from $8000-20000$. The results reveal that the combined effect of flow impingement and the suppression of formation of recirculation zone leads to increased heat transfer. Lower values of non-dimensional approach length and rib angle provides a higher thermal enhancement factor. The highest increase in Nusselt number is found to be about 1.82 times that of the smooth duct at $R e=8000$ for $h / e=0.25$ and rib angle of $15^{\circ}$. The maximum thermal enhancement factor is found to have a range of $1.6-1.45$ for an approach length of 0.25 and a rib angle of $15^{\circ}$.
\end{abstract}

ARTICLE HISTORY

Received: $31^{\text {st }}$ Dec 2020

Revised: $26^{\text {th }}$ Aug 2021

Accepted: $6^{\text {th }}$ Sept 2021

\section{KEYWORDS}

Clerestory rib;

Turbulence;

Solar air heater:

CFD;

Performance augmentation

\section{NOMENCLATURE}

$\mathrm{G}_{\mathrm{k}} \quad$ generation of turbulence kinetic energy

$\mathrm{L}$ duct length, $\mathrm{m}$

$\mathrm{Nu}_{\mathrm{s}} \quad$ Nusselt number for smooth duct

$\mathrm{Nu}_{\mathrm{r}} \quad$ Nusselt number for roughened duct

$\mathrm{p}$ pressure, $\mathrm{Pa}$

$\Delta \mathrm{p} \quad$ pressure drop, $\mathrm{Pa}$

Pr Prandtl number

$\mathrm{T}_{\mathrm{o}} \quad$ exit air temperature, $\mathrm{K}$

$\mathrm{T}_{\text {avg }} \quad$ average air temperature, $\mathrm{K}$

$\mathrm{T}_{\mathrm{p}} \quad$ plate temperature, $\mathrm{K}$

$\mathrm{Q}^{\prime} \quad$ heat flux, $\mathrm{Wm}^{-2}$

V mean air velocity, $\mathrm{ms}^{-1}$ $\mathrm{f}_{\mathrm{s}} \quad$ friction factor for smooth duct

$\mathrm{f}_{\mathrm{r}} \quad$ friction factor for roughened duct

$\mathrm{h} \quad$ rib approach length, $m$

$h_{c} \quad$ convective heat transfer coefficient, $\mathrm{Wm}^{-2} \mathrm{~K}$

$\mathrm{k} \quad$ turbulence Kinetic Energy, $\mathrm{m}^{2} \mathrm{~s}^{-2}$

$\mathrm{u} \quad$ velocity component, $\mathrm{ms}^{-1}$

Greek symbols

$\mu_{\mathrm{t}} \quad$ turbulent viscosity, $\mathrm{Nsm}^{-2}$

$\Gamma \quad$ molecular thermal diffusivity, $\mathrm{m}^{2} \mathrm{~s}^{-1}$

$\Gamma_{\mathrm{t}} \quad$ turbulent thermal diffusivity, $\mathrm{m}^{2} \mathrm{~s}^{-1}$

$\epsilon \quad$ rate of dissipation, $\mathrm{m}^{2} \mathrm{~s}^{-3}$

\section{INTRODUCTION}

Energy is so vital for humans in the $21^{\text {st }}$ century that it has become the fundamental necessity of modern life. Increasing energy demand, depleting fossil fuels, and global warming issues have made it imperative to utilise renewable energy to cater for the requirement of this fundamental necessity. Though solar radiation is the most abundant source of thermal energy on earth, harnessing it for useful purposes has been really inadequate due to large collector area requirements, low conversion efficiency, and limited thermal energy storage capabilities. The simplest way of harnessing direct solar thermal energy is through a solar air heater (SAH), which transfers the heat energy received from the solar radiation using an absorber plate to the continuous stream of air flowing through a duct. The SAH are simple devices for multiple applications like drying crops [1,2], drying fruits [3], drying fish [4], space heating [5,6], drying sewage sludge [7], and desalination of seawater [8]. However, the inherent limitation of SAH is the poor heat transfer properties of air which limits its performance. In addition, the suppression of convective mode of heat transfer by the presence of a laminar sublayer over the smooth heated surface further inhibits its efficacy.

The use of artificial roughness elements in the form of ribs on the absorber plate with their height proportional to the thickness of the viscous sub-layer can augment heat transfer and have been very commonly used by previous researchers owing to its effectiveness [9]. Obviously, the enhancement in thermal performance depends on the shape and size as well as the distribution density of these ribs as there is a trade-off between the heat energy gain by the fluid due to the breaking 
of viscous sub-layer and power loss incurred in the pumping of fluid over the ribs. This opens up a huge area of research to find the optimum shape, size and distribution density of rib turbulators.

The influence of ribs on the effective thermal performance of SAH has been extensively reported by many researchers and these roughness elements can be grouped into: transverse ribs [10-13], inclined ribs [14,15], arc-shaped ribs [16], Vshaped ribs[17], W-shaped ribs [18], discrete protrusions [19-21], discrete dimples [22,23] and winglets [24,25]. The ribs can be either continuous [26] or broken [27] and of uniform [26,28] or non-uniform [29,30] cross-section. The other surface modifications investigated include various corrugations [31,32] and combinations of rib and grooves [33]. In addition to that, some researchers have studied the effect of channel cross-section along with various ribs by considering triangular [34-36], semi-circular [35], and semi-cylindrical side wall ducts [37]. A comprehensive review on various methods and their comparative thermal performance analysis can be found in [38-42]. Although the transversely placed uniform cross-section rib turbulators generally have lower levels of heat transfer enhancement as compared to other rib arrangement patterns, they stand out on the front of ease of fabrication and lower pressure loss. An appropriate modification in the rib geometry could overcome the heat transfer limitations of transverse ribs to some extent. Various types of uniform cross-section transverse ribs of regular geometry have been reported in the literature include such as square [43], rectangular [44], triangular [45], circular [46,47], elliptical [48], reverse NACA [49], and semi-circular [50]. Each rib geometry has been found to have different levels of heat transfer performance and pressure losses owing to the varying impact on the resulting flow structure in the airflow.

Numerical studies on transverse ribs have shown that a closer look at the flow dynamics around the transverse ribs reveals the formation of entrapped eddies on either side of the rib, which causes local hot spots at the rib corner region that inhibits heat transfer. Few studies have suggested modifications to transverse ribs to suppress these eddies and thereby reduce hot spots to achieve increased heat transfer. Chaube et al. [51], through experiments and numerical simulations, showed that chamfering of ribs provide a relatively better performance, while Layek et al. [52] found that the chamfer angle of $18^{\circ}$ as the optimum angle for square ribs. Kumar et al. [53] numerically evaluated the performance of triangular cross-section duct using rectangular ribs that were chamfered on its top surface. Their results showed that the rib chamfer height ratio (ratio of left vertical edge ' $\mathrm{e}$ ' to the right vertical edge 'e') of 0.75 provides the optimum Nusselt number. Since chamfering of rib has a limited effect on the size of entrapped eddies, few studies have suggested the use of angled surface on the downstream side of rib to further reduce the size of entrapped eddies or possibly eliminate it. Bhagoria et al. [54] experimented using a transverse wedge-shaped rib and showed that heat transfer increases when the wedge angle on the downstream rib surface is maintained at $10^{\circ}$. Aghaie et al. [55] employed the well-known Taguchi method to optimise the geometry for the angled (trapezoidal) ribs using numerical simulation results. From the analysis, they concluded that a right-angled triangle-shaped rib (wedge-shaped rib) with a height-to-width ratio of 0.2 is the optimum configuration. For the rib height considered in their study, the wedge angle turns out to be about $11.3^{\circ}$. However, their optimisation of the trapezoidal rib geometry included rigidity in the form of two horizontal edges.

It is evident from the above reviewed literature that the chamfering of the top horizontal surface of square/rectangular ribs reduces the size of the entrapped eddy on the rib downstream, causing fluid to re-attach the absorber plate at a comparatively shorter distance. This reduces the hot spot area on the heated surface resulting in better energy transfer. Similarly, the wedge-shaped rib with a wedge angle varying between $10^{\circ}$ to $15^{\circ}$ performs better in terms of heat transfer due to increased suppression of downstream eddy formation. This inspires one to adopt similar techniques on the rib upstream surface as well to minimise the impeding effect of upstream eddy formation on heat transfer by making use of an isosceles triangular rib. However, the study performed by Min et al. [56], using inverse simulation technique to optimise the rib profile in a rectangular channel flow, reveals that the triangular shape is not the optimum shape for the rib. Their multi-point shape optimization yielded a new profile for the rib that always performed better than triangular ribs.

Thus, it is clear that merely using an angled surface on the upstream side of the rib does not ensure improvement in heat transfer and a more detailed study is needed to arrive at a proper rib upstream surface geometry modification that could impact heat transfer and reduce pressure loss. To the best of the author's knowledge, no such studies have been reported in the past pertinent to solar air heater application. Thus, the objective of the present study is to evaluate the influence of rib upstream surface modifications using novel clerestory shaped ribs for the enhancement of heat transfer in a rectangular duct SAH using CFD methodology. A two-dimensional numerical analysis is carried out to determine the influence of a novel transversely placed clerestory shaped rib on the thermal performance of a rectangular solar air heater duct. The rib upstream surface consists of two parts where the upper part is always normal to the flow while the bottom part is inclined to the incoming flow. The effect of inclination of bottom rib surface as well as the height of the vertical rib surface on heat transfer, friction factor penalty and thermal enhancement factor is brought out for the Reynolds number range of 8000-20000.

\section{CFD METHODOLOGY}

\section{Description of Computational Domain}

A typical solar air heater consists of an absorber plate fitted on top of the rectangular air duct, as shown in Figure 1(a). The air duct is provided with insulation around the duct to reduce heat loss by conduction and convection. Radiation heat losses can be reduced by placing glass cover on top of absorber plate with some air gap between the absorber plate and glass cover. The inclination of the air heater duct is typically the latitude angle of the location. This air heater system is 
taken up for further analysis by considering an inlet and exit section attached to it for the sake of numerical analysis. The inlet section helps to stabilise the incoming flow and allow it to reach fully developed conditions.

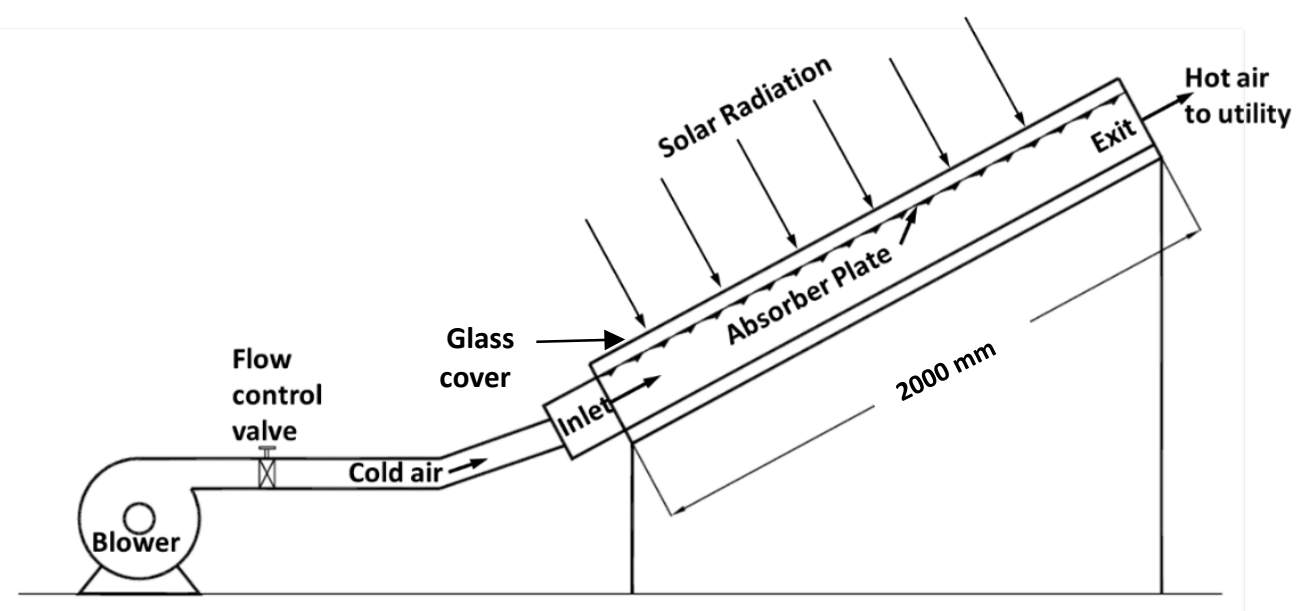

(a) forced convection solar air heater system

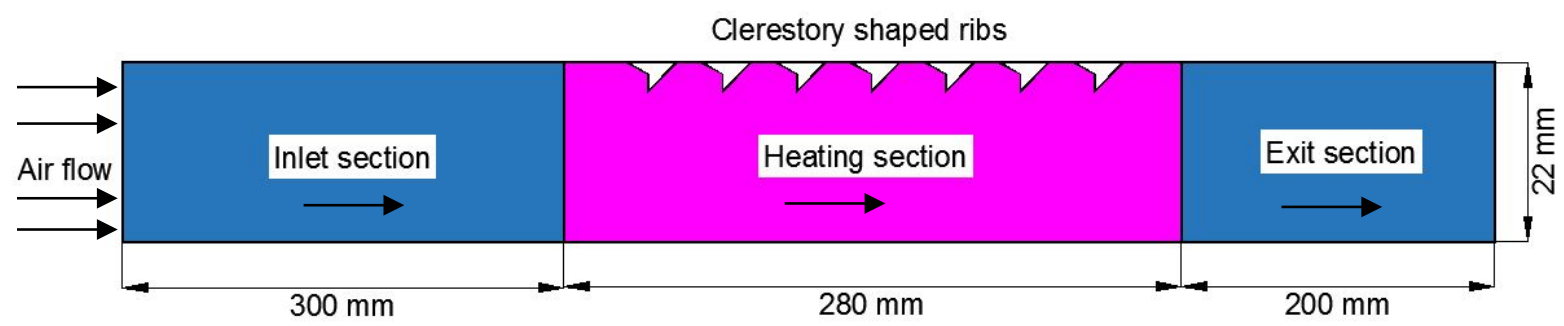

(b) details of two-dimensional computational domain of rectangular air heater duct (not to scale)

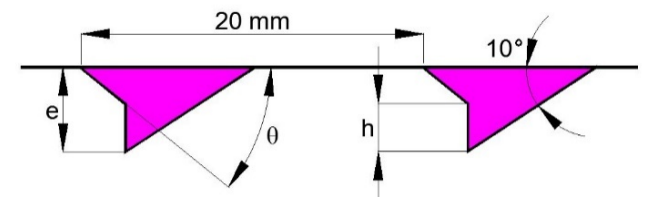

(c) geometric details of clerestory shaped ribs
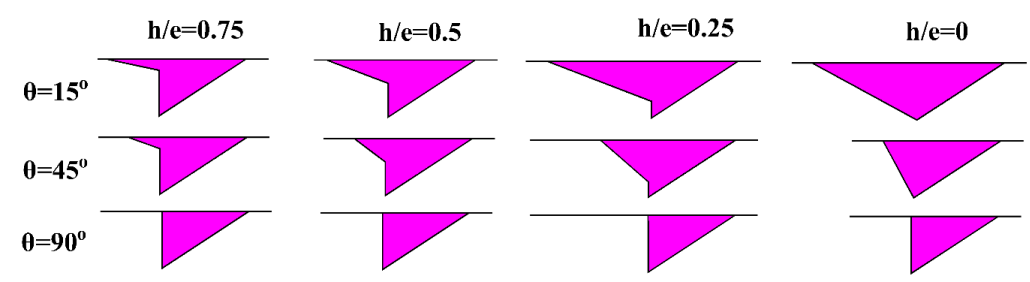

(d) various rib configurations used in the analysis

Figure 1. Constructional and geometric details of solar air heater system fitted with clerestory ribs.

The numerical analysis is carried out on the two-dimensional flow domain of rectangular duct SAH. The geometric details of the two-dimensional air heater duct are shown in Figure 1(b). The duct consists of three divisions such as entry section, heating section and exit section. The entry section is provided to aid the flow to develop fully before the heating section, and the length is selected as $300 \mathrm{~mm}$ as per Eq. (1), which provides the minimum length of entry section required to ensure fully developed turbulent flow [54]. The exit section length is selected as $200 \mathrm{~mm}$ as per Eq. (2), and the heating section length is chosen as $280 \mathrm{~mm}$. The width $(\mathrm{W})$ and height $(\mathrm{H})$ of the duct are fixed as $150 \mathrm{~mm}$ and $22 \mathrm{~mm}$, respectively, and the hydraulic diameter of the duct is $38 \mathrm{~mm}$. The hydraulic diameter of rectangular duct is found using Eq. (3).

Entry section length $\geq 5 \sqrt{W H}$

Exit section length $\geq 2.5 \sqrt{W H}$

Hydraulic dimeter $\left(\mathrm{D}_{\mathrm{h}}\right)=\frac{4 W H}{2(W+H)}$ 
The test section is provided with transversely placed clerestory shaped ribs, as shown in Figure 1(b). A close-up view of the rib is depicted in Figure 1(c). The pitch of the rib is fixed as $20 \mathrm{~mm}$, which corresponds to the relative roughness pitch $(\mathrm{P} / \mathrm{e})$ of 12.5 , while the total rib height is fixed at $1.6 \mathrm{~mm}$, which corresponds to the relative roughness height value $\left(\mathrm{e} / \mathrm{D}_{\mathrm{h}}\right)$ of 0.0421 . The downstream rib surface is inclined at a fixed angle of $10^{\circ}$, which is the optimal inclination for augmented heat transfer as reported by Bhagoria et al. [54]. The upstream surface of the rib consists of two parts in which the lower part is inclined to the flow at three different angles $(\theta)$ of $15^{\circ}, 45^{\circ}$ and $90^{\circ}$ while the upper part is always normal to the incoming airflow as shown in Figure1(c). The non-dimensional approach length (h/e) of the upper part of the rib upstream surface is varied as $0,0.25,0.5$ and 0.75 . Table 1 gives an overview of various geometric parameters of rib considered in the analysis. The various configurations of ribs obtained for different combinations of rib angle $(\theta)$ and non-dimensional approach length (h/e) are shown in Figure 1(d). A rib angle of $90^{\circ}$ leads to the rib geometry of a rightangled triangle for all values of approach length. Similarly, the non-dimensional approach length of zero leads to the rib geometry of a scalene triangle for all rib angles.

Table 1. Details of various rib parameters used in the analysis.

\begin{tabular}{lc}
\hline Parameters & Value \\
\hline Rib height $(\mathrm{e})$ & $1.6 \mathrm{~mm}$ \\
Relative roughness height $\left(\mathrm{e} / \mathrm{D}_{\mathrm{h}}\right)$ & 0.0421 \\
Rib pitch $(\mathrm{P})$ & $20 \mathrm{~mm}$ \\
Relative roughness pitch $(\mathrm{P} / \mathrm{e})$ & 12.5 \\
Non-dimensional approach length $(\mathrm{h} / \mathrm{e})$ & $0,0.25,0.5$ and 0.75 \\
Rib angle $(\theta)$ & $15^{\circ}, 45^{\circ}$ and $90^{\circ}$ \\
\hline
\end{tabular}

\section{Assumptions}

The analysis is carried out using the following assumptions:

i. Air is assumed as an ideal gas, and the flow is steady, turbulent and incompressible.

ii. The thermo-physical properties of air are assumed to be constant.

iii. Since the air heater duct walls are usually thermally well insulated, the heat loss from the duct to surroundings is neglected in the analysis.

iv. The radiation heat exchange between the air stream and duct walls is neglected.

v. The effect of gravity on the flow is neglected.

vi. The effect of glass cover with reference to convective and radiative heat losses are neglected.

vii. The effect of radiation heat loss is neglected.

viii. The effect of coatings on plate and glass cover is neglected.

\section{Boundary Conditions and Solution Techniques}

The boundary conditions specified in the computational domain is outlined in Table 2 . The analysis is carried out using the software tool ANSYS Fluent, which makes use of finite volume method for discretisation of governing equations. The governing equations for flow and energy are discretised using second-order upwind schemes. RNG k- $\epsilon$ turbulence model with enhanced wall treatment has been widely used in the literature $[43,45,48]$ to characterise the flow turbulence in solar air heater studies involving rib turbulators which involves flow separation and recirculation. Hence, RNG k- $\epsilon$ turbulence model with enhanced wall treatment is adopted in the present study as well. The thermo-physical properties of air at the inlet air temperature of $300 \mathrm{~K}$ are listed in Table 3 . The input parameters for turbulence model is specified using hydraulic diameter and turbulence intensity and the turbulence intensity in the core region of the flow is determined using Eq. (4) for a fully developed turbulent flow as suggested by the Ansys Fluent user manual [58].

Table 2. Boundary conditions.

\begin{tabular}{|c|c|c|c|}
\hline Sl. No. & Boundary Name & Boundary type & Condition used \\
\hline 1. & Duct inlet & Velocity inlet & $\begin{array}{l}\text { Uniform velocity of air is specified at the inlet and is varied from } 3.3 \\
\mathrm{~m} / \mathrm{s} \text { to } 8.25 \mathrm{~m} / \mathrm{s} \text { which corresponds to the Reynolds number of } 8000 \\
\text { to } 20000 \text {. The inlet temperature of air is taken as } 300 \mathrm{~K} \text {. }\end{array}$ \\
\hline 2. & Duct exit & Pressure outlet & $\begin{array}{l}\text { A pressure value of } 101325 \mathrm{~Pa} \text { is specified to simulate the } \\
\text { atmospheric pressure conditions to which the heated air is exited. }\end{array}$ \\
\hline 3. & Absorber plate & Heat flux & $\begin{array}{c}\text { A constant heat flux value of } 800 \mathrm{~W} / \mathrm{m}^{2} \text { is specified. This heat flux } \\
\text { simulates the average solar heat flux encountered by a solar air } \\
\text { heater. }\end{array}$ \\
\hline 4. & $\begin{array}{l}\text { Remaining } \\
\text { boundaries }\end{array}$ & Wall & $\begin{array}{l}\text { Thermally insulated wall with heat flux specification of } 0 \mathrm{~W} / \mathrm{m}^{2} \text {. A } \\
\text { no-slip condition is also specified. }\end{array}$ \\
\hline
\end{tabular}

$$
\text { Turbulence intensity }=\frac{0.16}{R e^{-0.125}}
$$

where the flow Reynolds number (Re) is determined using Eq. (5). 


$$
\operatorname{Re}=\frac{\left(\rho \mathrm{DD}_{h}\right)}{\mu}
$$

Table 3. Thermo-physical properties of air

\begin{tabular}{lc}
\hline Property & Value \\
\hline Density $(\rho)$ & $1.18 \mathrm{kgm}^{-3}$ \\
Dynamic viscosity $(\mu)$ & $0.0000185 \mathrm{Kgs}^{-1} \mathrm{~m}^{-1}$ \\
Thermal conductivity $\left(\mathrm{k}_{\mathrm{t}}\right)$ & $0.02624 \mathrm{Wm}^{-1} \mathrm{~K}^{-1}$ \\
Specific heat $\left(\mathrm{C}_{\mathrm{p}}\right)$ & $1006 \mathrm{Jkg}^{-1} \mathrm{~K}^{-1}$ \\
\hline
\end{tabular}

\section{Governing Equations}

The equations that govern the two-dimensional flow in a steady incompressible flow is given below:

Continuity equation:

$$
\frac{\partial}{\partial x_{i}}\left(\rho u_{i}\right)=0
$$

Momentum equation:

$$
\frac{\partial}{\partial x_{i}}\left(\rho u_{i} u_{j}\right)=-\frac{\partial p}{\partial x_{i}}+\frac{\partial}{\partial x_{j}}\left[\mu_{e f f}\left(\frac{\partial u_{i}}{\partial x_{j}}+\frac{\partial u_{j}}{\partial x_{i}}\right)\right]+\frac{\partial}{\partial x_{j}}\left(\overline{-\rho u_{i}^{\prime} u_{j}^{\prime}}\right)
$$

Energy equation:

$$
\frac{\partial}{\partial x_{i}}\left(\rho u_{i} T\right)=\frac{\partial}{\partial x_{j}}\left[\left(\Gamma+\Gamma_{t}\right) \frac{\partial T}{\partial x_{j}}\right]
$$

The RNG k- $\varepsilon$ turbulence model:

$$
\begin{gathered}
\frac{\partial}{\partial x_{i}}\left(\rho k u_{i}\right)=\frac{\partial}{\partial x_{j}}\left(\alpha_{k} \mu_{e f f} \frac{\partial k}{\partial x_{j}}\right)+G_{k}-\rho \varepsilon \\
\frac{\partial}{\partial x_{i}}\left(\rho \varepsilon u_{i}\right)=\frac{\partial}{\partial x_{j}}\left(\alpha_{\varepsilon} \mu_{e f f} \frac{\partial \varepsilon}{\partial x_{j}}\right)+C_{1 \varepsilon} \frac{\varepsilon}{k} G_{k}-C_{2 \varepsilon} \rho \frac{\varepsilon^{2}}{k}-R_{\varepsilon}
\end{gathered}
$$

The effective viscosity is given by,

$$
\mu_{e f f}=\mu+\mu_{t}
$$

The turbulent viscosity is given by,

$$
\mu_{t}=\rho C_{\mu} \frac{k^{2}}{\varepsilon}
$$

The value of the constants in the above equations are given by $\mathrm{C}_{1 \epsilon}=1.42, \mathrm{C}_{2 \epsilon}=1.68$ and $\mathrm{C}_{\mu}=0.0845$.

\section{Grid Independence Test and Validation of CFD Model}

The results obtained from the CFD model needs to be grid-independent so as to have a unique solution, and a grid independence test needs to be carried out to ensure this. The present CFD model is based on the author's previous work [57], where a two-dimensional numerical analysis was carried out for solar air heater with circular ribs and U-shaped ribs. The authors had conducted a detailed grid independence test in the presence of circular ribs and determined that the computational domain must have at least 144557 control volumes to guarantee that the solution is unique. Further, the results of CFD model with circular ribs were validated against the experimental results of Gupta et al. [47] with an average deviation of $8.31 \%$ for Nusselt number and $4.51 \%$ for friction factor for the flow Reynolds number range of $9000-21000$. The present CFD model makes use of the same duct geometry, meshing techniques, numerical schemes and boundary conditions for which the validation study was conducted in their previous work, except that the circular rib is now replaced with clerestory shaped ribs. Figure 2 shows the discretised computational domain of present work with a close-up view of meshing around the clerestory shaped rib. Inflation feature of the software tool is used to resolve the boundary layer region and finer elements are provided around the rib region to capture the flow gradients. 


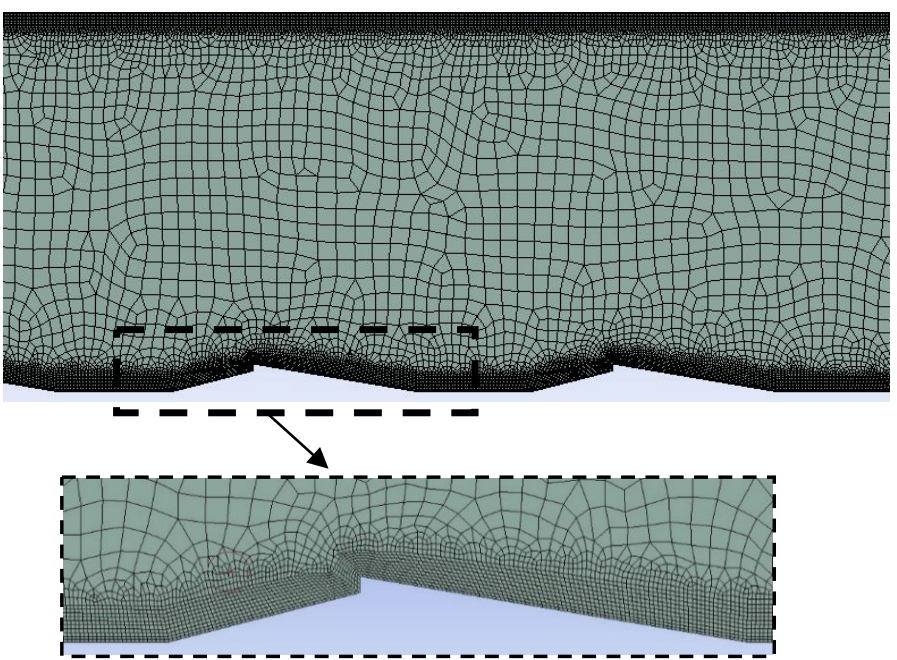

Figure 2. Discretised flow domain in the presence of clerestory ribs.

\section{RESULTS AND DISCUSSION}

A two dimensional CFD analysis is carried out to evaluate the efficacy of rib upstream surface modifications of a novel clerestory shaped rib that are placed transversely on the absorber plate of the heating section of a rectangular duct solar air heater. The results of Nusselt number, friction factor and thermal enhancement factor for various rib configurations are presented for the Reynolds number range of 8000-20000.

\section{Heat Transfer Characteristics}

\section{Effect of variation of rib angle for a given non-dimensional approach length}

The influence of variation of rib angle on Nusselt number for a given non-dimensional approach length of $\mathrm{h} / \mathrm{e}=0,0.25$, 0.5 and 0.75 for different Reynolds number conditions is shown in Figure 3(a), Figure 3(b), Figure 3(c) and Figure 3(d) respectively. From Figure 3, it is clear that the use of clerestory shaped ribs significantly enhances the heat transfer over the smooth duct for all configurations used in the analysis. The Nusselt number for smooth duct is determined using the well-known Dittus-Boelter equation and is given by Eq. (12). The Nusselt number for the duct with ribs is determined using Eq. (13).

$$
\begin{gathered}
N u_{s}=0.023 \operatorname{Re}^{0.8} \operatorname{Pr}^{0.4} \\
N u_{r}=\frac{h_{c} D_{h}}{k_{t}} \\
h_{c}=\frac{Q^{\prime}}{\left(T_{p}-T_{\text {avg }}\right)}
\end{gathered}
$$

where the average air temperature is given by, $T_{a v g}=\frac{\left(T_{i}+T_{o}\right)}{2}$. For the case of smooth duct, the flow near the heated wall is undisturbed throughout the heated length and the presence of a laminar sublayer within the turbulent boundary layer impede the transfer of heat to the flowing air stream. However, in the presence of ribs, the boundary layer is disturbed at several locations, thereby creating fluid agitation, which enhances energy transfer to the flowing air stream. Thus, increased turbulence levels in the airflow in the presence of ribs improve heat transfer relative to the smooth duct, as indicated in Figure 3. From Figure 3(b), it is interesting to note that the Nusselt number increases with decreasing values of rib angle for a given approach length of $\mathrm{h} / \mathrm{e}=0.25$.

This can be explained with reference to Figure 4, which shows the comparison of velocity streamlines for the rib angle of $15^{\circ}, 45^{\circ}$ and $90^{\circ}$ and $\mathrm{h} / \mathrm{e}=0.25$. From Figure $4(\mathrm{a})$, it is observed that for the rib angle of $90^{\circ}$, the entire upstream surface of the rib is normal to the incoming air stream as a result of which the air stream as it impacts the rib surface gets partly deflected to the bottom of the rib while the rest of the air moves upward along the rib. The deflected air stream gets entrapped at the rib corner region leading to the formation of a large primary recirculation zone along with a smaller counter-rotating secondary recirculation zone, as shown in Figure 4(a). The air stream in the recirculation zone remains detached from the main flow and hence have a relatively lower velocity, as seen in Figure 4(a) as a result of which the heat removal rate from the heated wall which is in contact with the recirculation zone decreases. In addition, due to the entrapment of the air stream within the recirculation zone, the air temperature rises locally, which further impedes the heat transfer between the heated wall and the recirculation zone owing to the reduced temperature differential. As a result, hot spots are formed within the recirculation zone as revealed by the temperature distribution plot in Figure 5(a), and these hot spots are found to be significantly higher in temperature as compared to the main flow and are seen all along 
the length of the recirculation zone and characterize the locations of reduced heat transfer. Thus, due to the formation of a large entrapped recirculation zone associated with hot spots, the Nusselt number is relatively lower for the rib angle of $90^{\circ}$. As the rib angle decreases from $90^{\circ}$ to $45^{\circ}$, the upstream bottom surface of the rib gets less steep, thereby aligning itself relatively more with the incoming air stream.

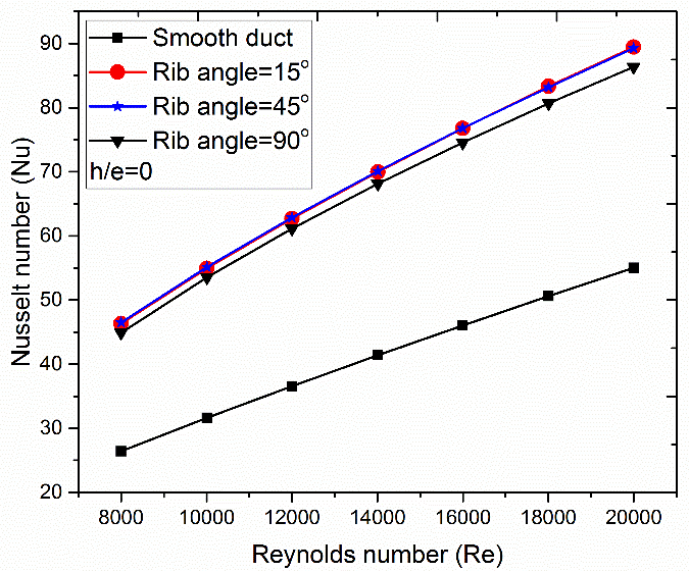

(a) $h / e=0$

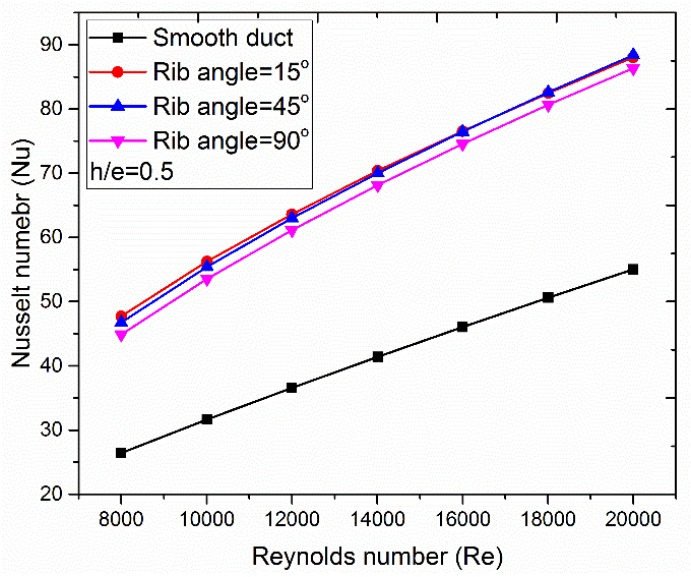

(c) $h / e=0.5$

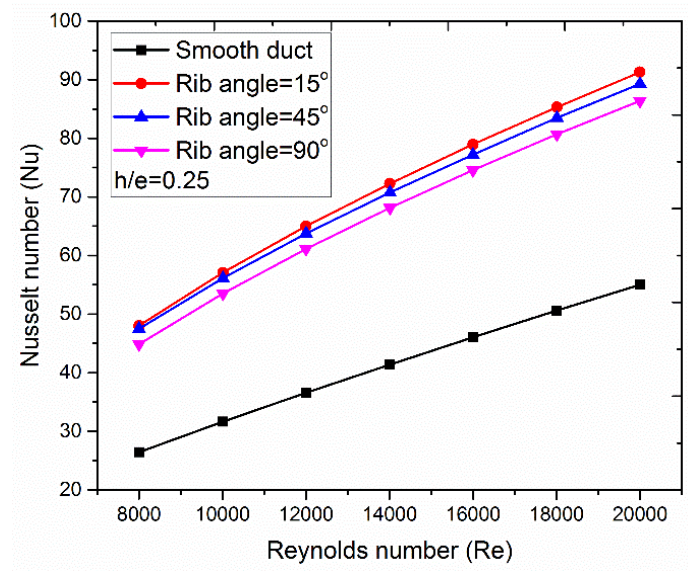

(b) $\mathrm{h} / \mathrm{e}=0.25$

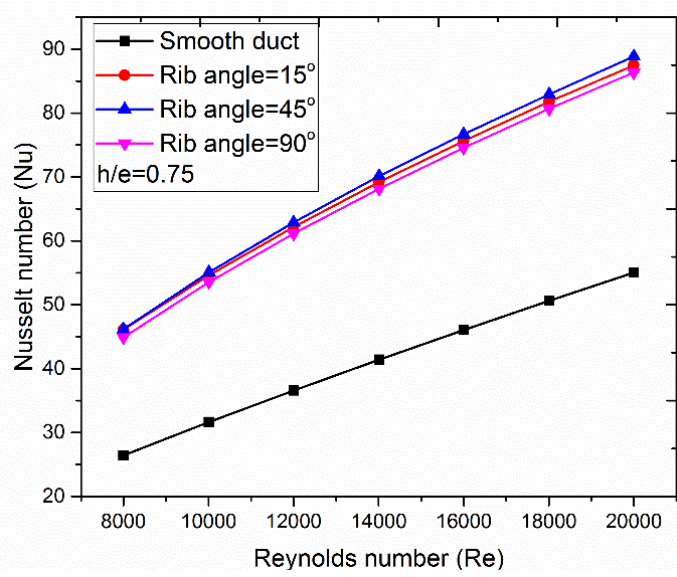

(d) $\mathrm{h} / \mathrm{e}=0.75$

Figure 3. Influence of rib angle on the variation of Nusselt number for the non-dimensional approach length (h/e).

\section{Flow direction}
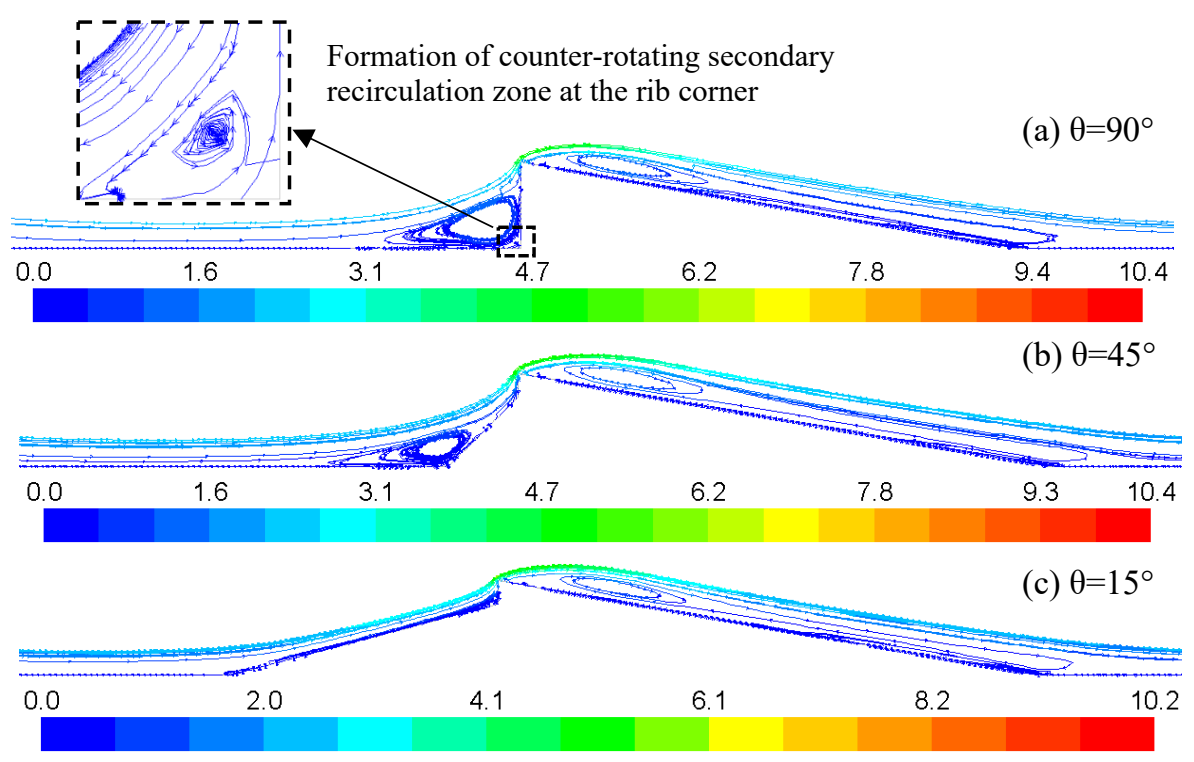

Figure 4. Comparison of flow streamlines (coloured by velocity) for $\mathrm{h} / \mathrm{e}=0.25$ and different rib angles. 
As a result, the air glides over the inclined upstream surface relatively smoothly with reduced flow deflection upon impact with the inclined surface which reduces the size of the recirculation zone as depicted in Figure 4(b). Reduced size of the recirculation zone in turn, results in the reduction of hot spots, as revealed in Figure 5(b). With further reduction of rib angle from $45^{\circ}$ to $15^{\circ}$, it is observed that the upstream bottom surface of the rib is significantly well aligned with the incoming airflow. This makes the flow smoothly glide over the inclined rib upstream surface with negligible flow deflection thereby nearly eliminating the formation of recirculation zone, as shown in Figure 4(c) and also overcomes the formation of hotspots as seen in Figure 5(c). Hence, the rib angle of $15^{\circ}$ is found to produce relatively higher values of Nusselt number as compared to that of $45^{\circ}$ and $90^{\circ}$.

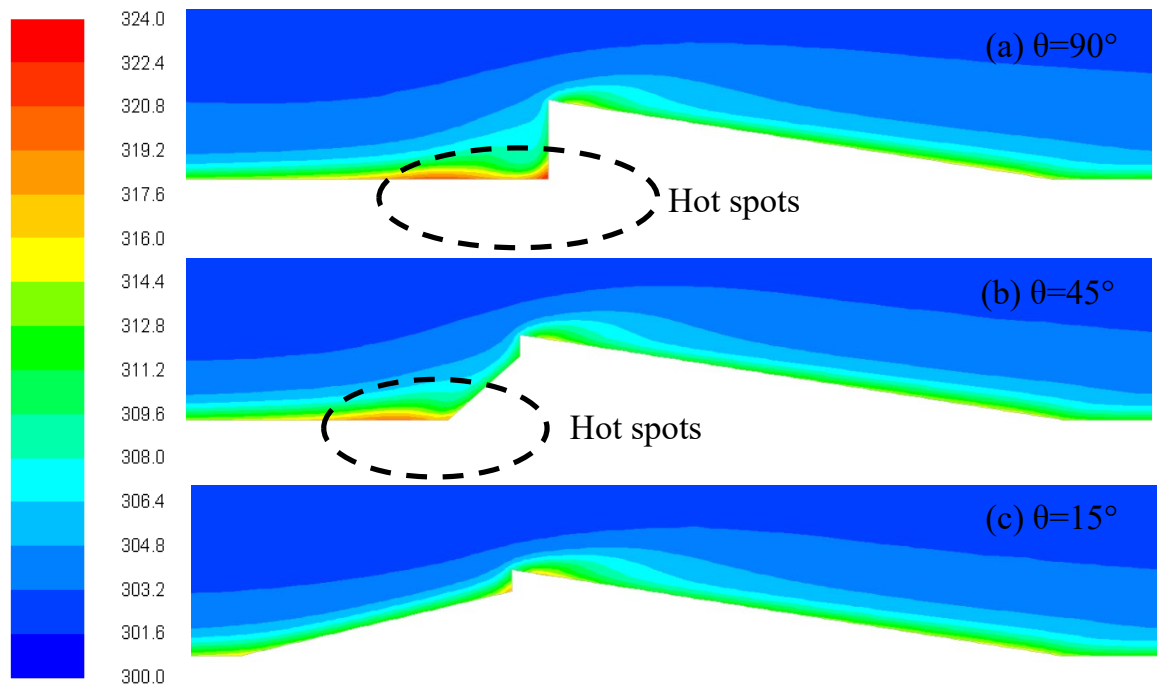

Figure 5. Comparison of temperature distribution in the airflow around the ribs for $\mathrm{h} / \mathrm{e}=0.25$ and different rib angles.

Further insight into this behaviour can be obtained from Figure 6, which shows the variation of convective heat transfer coefficient along the rib surface for the rib angle of $15^{\circ}, 45^{\circ}$ and $90^{\circ}$ and $\mathrm{h} / \mathrm{e}=0.25$. The heat transfer coefficient is plotted for the pitch distance of $20 \mathrm{~mm}$ between the downstream ends of the $6^{\text {th }}$ and $7^{\text {th }}$ ribs. From the figure, it is noted that the heat transfer coefficient is significantly higher for a greater length of the inclined rib upstream surface for the rib angle of $15^{\circ}$ owing to a significant reduction of recirculation zone while there is great depression in the values of heat transfer coefficient along the same non-dimensional length for the rib angle of $45^{\circ}$ and $90^{\circ}$. Also, the heat transfer coefficient is found to spike along the upstream vertical surface due to the flow impingement effect and is relatively higher for the rib angle of $90^{\circ}$ and is followed by the rib angle of $45^{\circ}$ and $15^{\circ}$. However, such a spike occurs only for a shorter length along the vertical rib surface and is found to have limited effect. It is also interesting to see that the variation of heat transfer coefficient is similar on the downstream rib surface with a negligible difference for all the three rib angles used in the analysis. Thus, for a given non-dimensional approach length of 0.25 , the rib angle of $15^{\circ}$ produces greater heat transfer owing to increased suppression of recirculation zone and exhibits the highest increase in Nusselt number by about 1.82 times that of the smooth duct at $\mathrm{Re}=8000$.

Further, from Figure 3(a) to Figure 3(d), it can be seen that the rib angle of $90^{\circ}$ always refers to the case of rightangled triangle rib geometry and produces a lower Nusselt number when compared to $45^{\circ}$ and $15^{\circ}$ for all values of h/e; due to larger recirculation zone formation at their upstream side. However, for the case of $\mathrm{h} / \mathrm{e}=0$, the resulting rib geometry is that of a scalene triangle, and hence the difference in Nusselt number is negligible for rib angles of $45^{\circ}$ and $15^{\circ}$ due to similar flow structure on its upstream surface and differs only with that of $90^{\circ}$ angle as the rib geometry transforms to a right-angled triangle. On the other hand, for higher values of $\mathrm{h} / \mathrm{e}=0.5$ and 0.75 , the resulting geometry modification achieved through rib angle variation does not produce a significant change in the flow structure, and hence all the rib angles exhibit closer values of Nusselt number and are found to perform lower than that of $\mathrm{h} / \mathrm{e}=0.25$.

\section{Effect of variation of non-dimensional approach length for a given rib angle}

Figure 7 (a) shows the influence of non-dimensional approach length on the Nusselt number for a given rib angle of $15^{\circ}$. It is seen that the Nusselt number increases as the approach length increases from $\mathrm{h} / \mathrm{e}=0$ to $\mathrm{h} / \mathrm{e}=0.25$. However, the Nusselt number decreases with a further increase of approach length from 0.5 to 0.75 . This can be explained with reference to Figure 8, which shows the velocity streamlines over the rib for the edge angle of $15^{\circ}$ and different approach length (h/e) of $0,0.25,0.5$ and 0.75 . From Figure $8(\mathrm{a})$, it is seen that for $\mathrm{h} / \mathrm{e}=0$, the rib geometry is effectively a scalene triangle and the incoming air flow smoothly flows over the upstream surface with no recirculation zone formation resulting in negligible hot spots as is evident in Figure 9(a). However, the incoming air stream will have a negligible flow impingement effect on the inclined rib upstream surface, which generally causes a local spike in heat transfer coefficient in the presence of ribs. For the case of $\mathrm{h} / \mathrm{e}=0.25$, the inclined rib surface is no longer connected to the tip of the rib as shown in Figure 8(b) and therefore provides a vertical surface from the tip of the rib, which has a length of $25 \%$ of the total rib height. The incoming air stream slaps itself on this upstream vertical surface, thereby causing a flow impingement effect which leads to augmented heat transfer. 


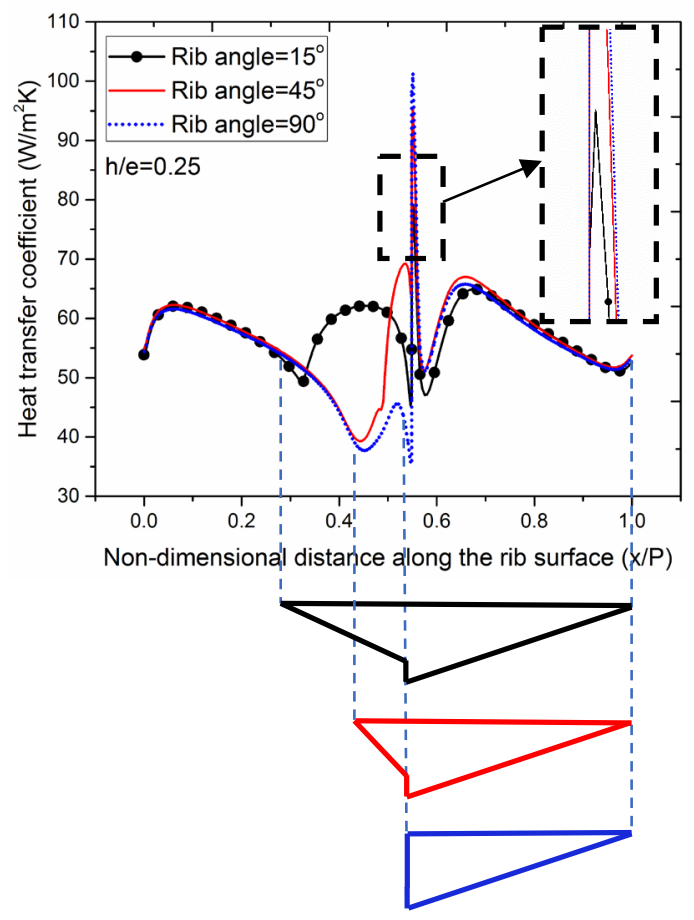

Figure 6. Comparison of variation of heat transfer co-efficient along the rib profile for $\mathrm{h} / \mathrm{e}=0.25$ and different rib angles of $15^{\circ}, 45^{\circ}$ and $90^{\circ}$.

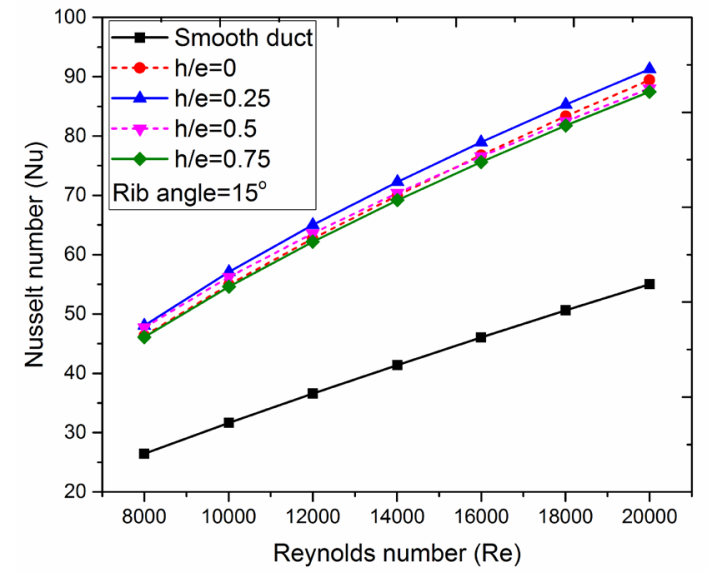

(a) $15^{\circ}$

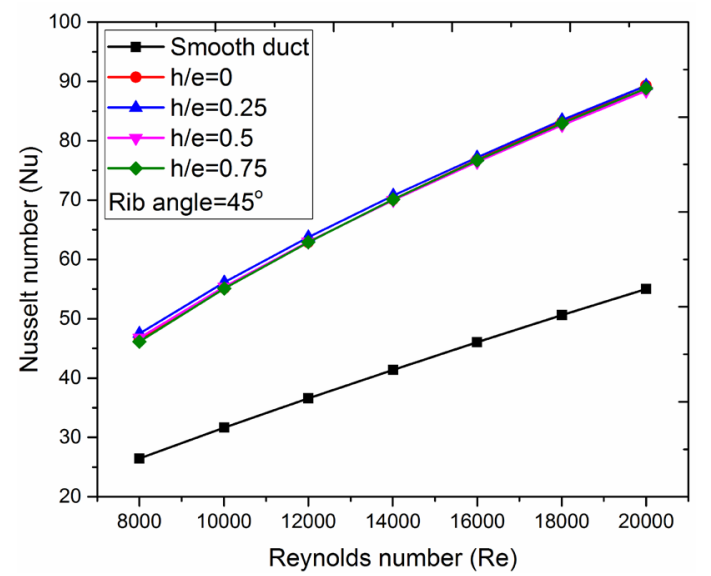

(b) $45^{\circ}$

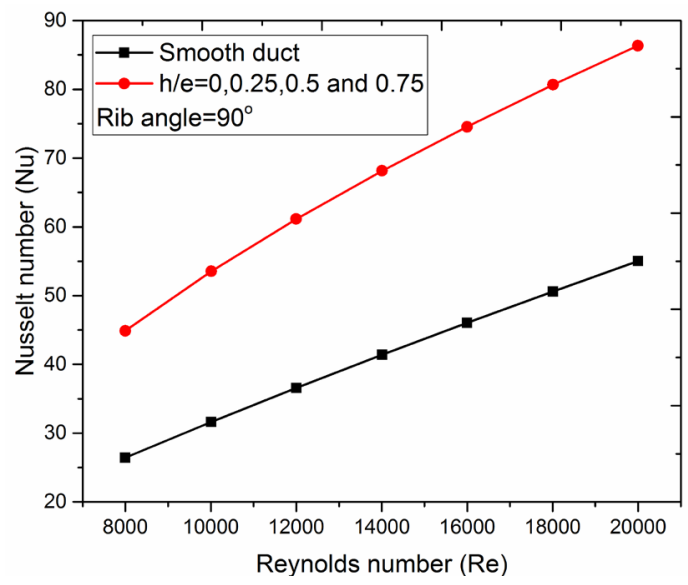

(c) $90^{\circ}$

Figure 7. Influence of non-dimensional approach length on the variation of Nusselt number for different rib angles.

Moreover, the formation of entrapped recirculation zone at the rib corners are also found to be negligible. In addition, the hot spot formation is also negligible for $\mathrm{h} / \mathrm{e}=0.25$, as is evident from Figure $9(\mathrm{~b})$. However, as the approach length increases to 0.5 , larger entrapped recirculation zones appear at the base region of rib as well as at the junction of the 
upstream vertical and inclined surface, as shown in Figure8(c). This effect is even more pronounced for $\mathrm{h} / \mathrm{e}=0.75$ as seen in Figure 8(d) and both the rib configuration having $\mathrm{h} / \mathrm{e}=0.5$ and 0.75 exhibits larger hot spot formation, which impede the heat transfer as shown in Figure 9(c) and Figure 9(d), respectively. Thus, it is clear that the combined effect of flow impingement and suppression of the formation of the recirculation zone leads to increased heat transfer. The rib configuration of $\mathrm{h} / \mathrm{e}=0.25$ exhibits both these effects as compared to $\mathrm{h} / \mathrm{e}=0.5$ and 0.75 and exhibits increase of heat transfer.

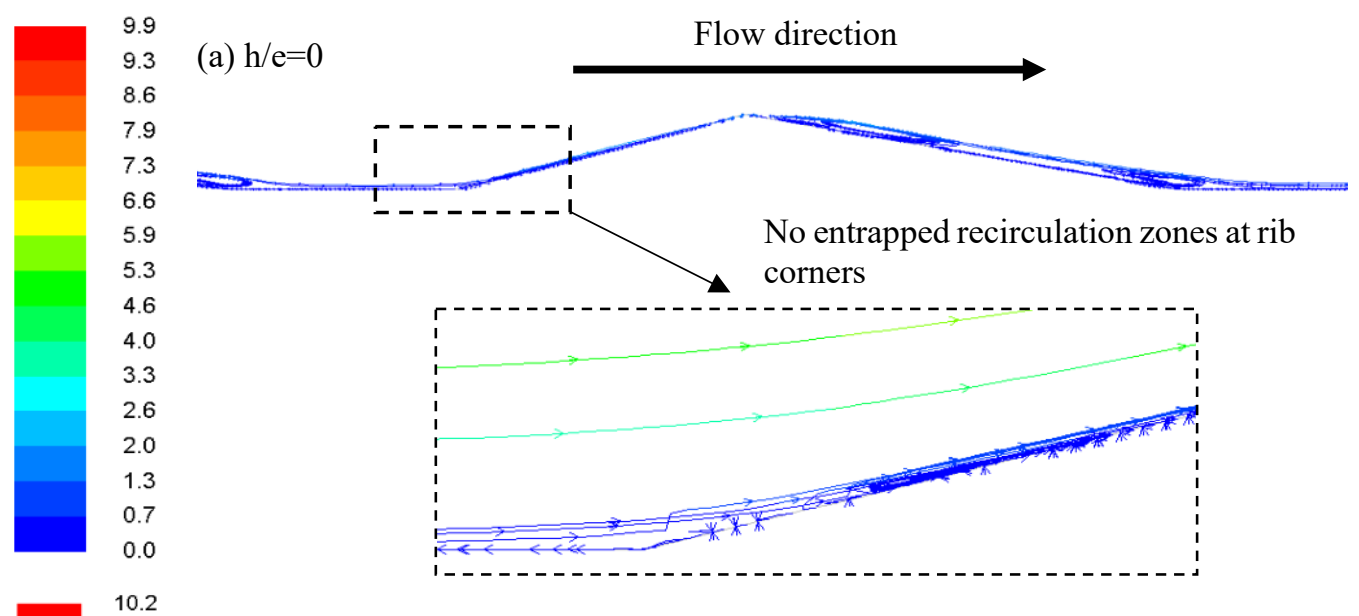

(b) $\mathrm{h} / \mathrm{e}=0.25$
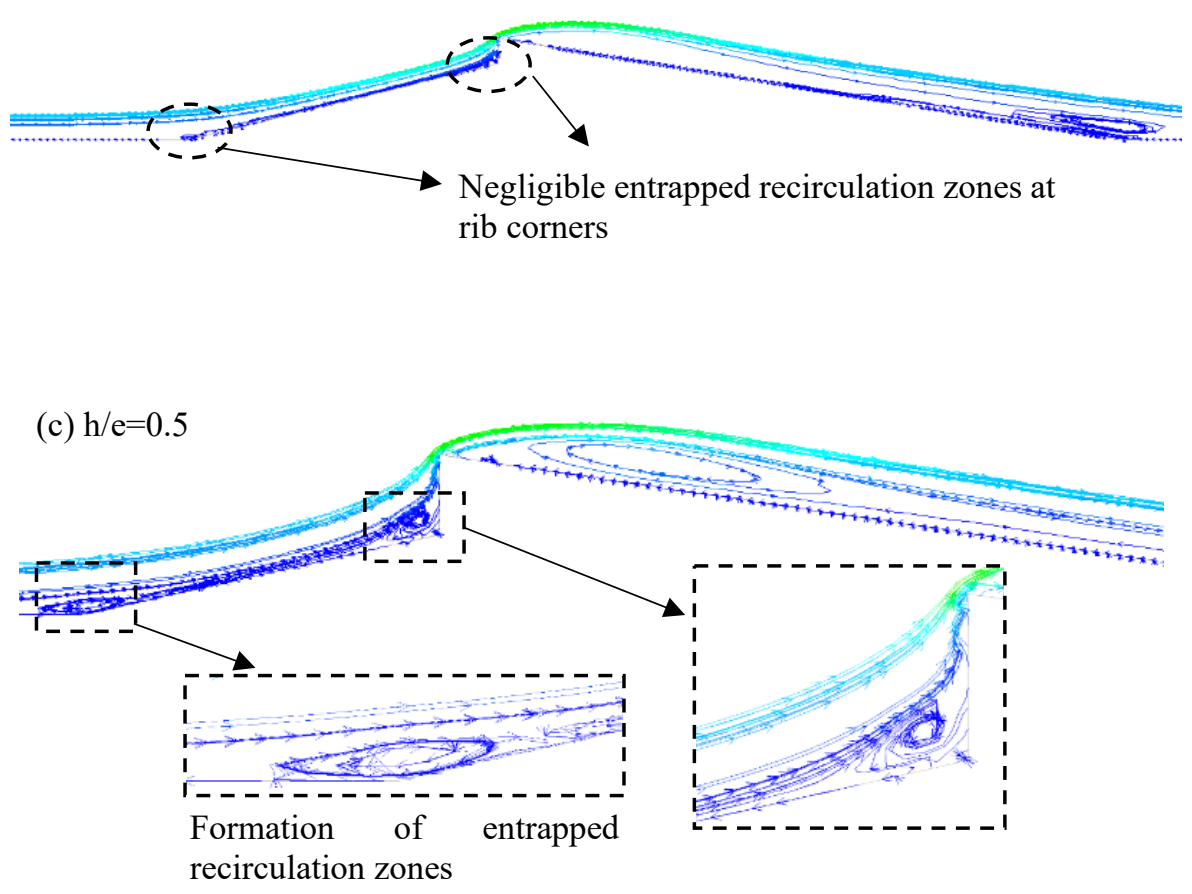

(d) $\mathrm{h} / \mathrm{e}=0.75$

Figure 8. Comparison of flow streamlines for the rib angle of $15^{\circ}$ and different non-dimensional approach length (h/e) of $0,0.25,0.5$ and 0.75 . 


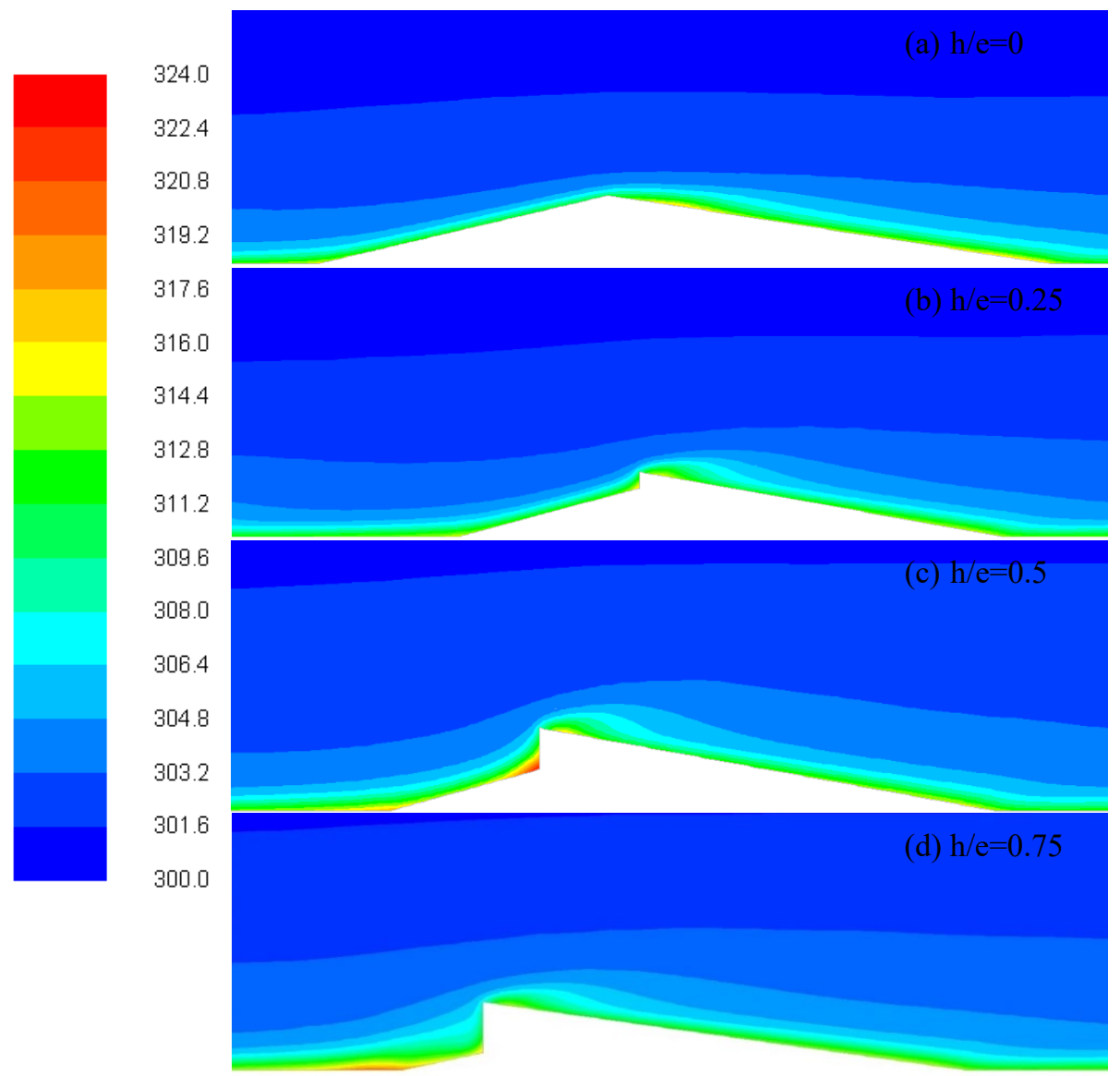

Figure 9. Comparison of temperature distribution in the airflow around the ribs for rib angle of $15^{\circ}$ and different nondimensional approach lengths $(\mathrm{h} / \mathrm{e})$ of $0,0.25,0.5$ and 0.75 .

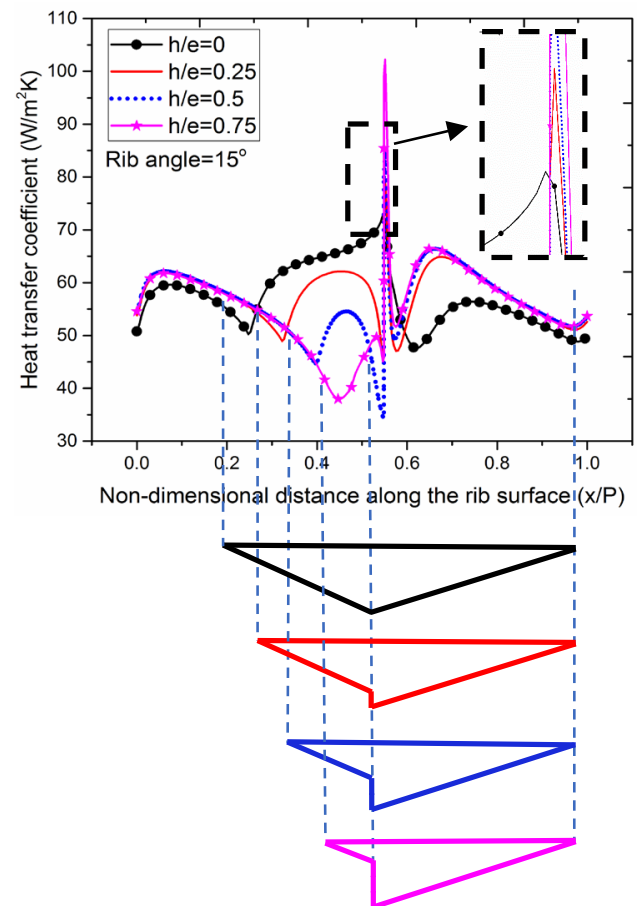

(a) variation of heat transfer coefficient along the rib profile for rib angle of $15^{\circ}$ and different non-dimensional approach length $(\mathrm{h} / \mathrm{e})$ of $0,0.25,0.5$ and 0.75 . 

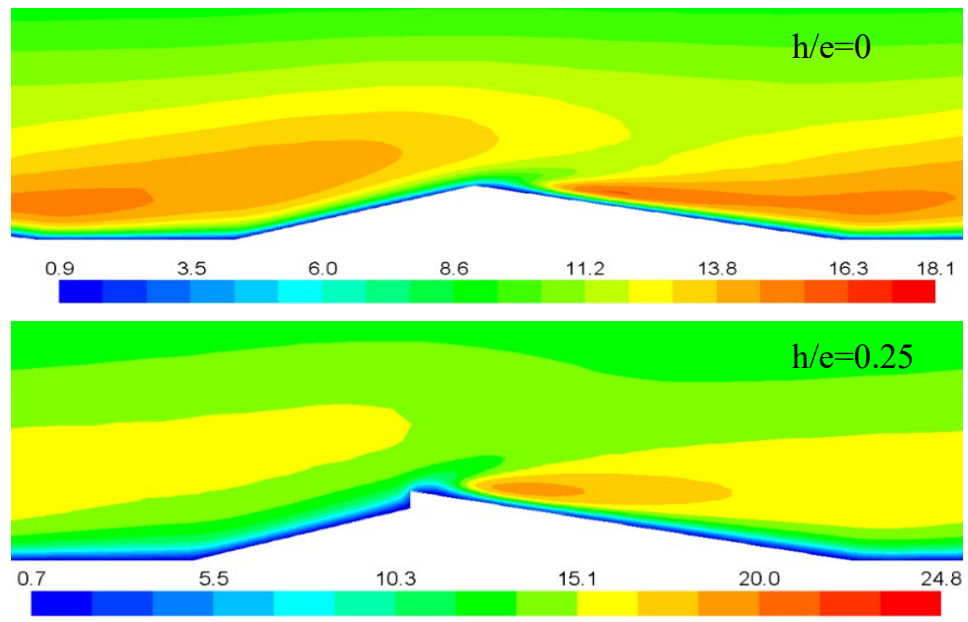

(b) turbulence intensity (\%) around the rib region for rib angle of $15^{\circ}$ and $\mathrm{h} / \mathrm{e}=0$ and 0.25

Figure 10. Comparison of variation of heat transfer co-efficient and turbulence intensity.

Further insight into this behaviour can be obtained from Figure 10(a), which shows the comparison of variation of heat transfer coefficient along the rib surface for the pitch distance of $20 \mathrm{~mm}$ between the consecutive downstream ends of the $6^{\text {th }}$ and $7^{\text {th }}$ rib. It can be seen that the heat transfer coefficient is relatively higher for $\mathrm{h} / \mathrm{e}=0$ on the upstream side of the rib. However, due to the absence of flow impingement effect, there is a negligible spike in heat transfer coefficient at the rib tip as compared to all other configurations of the rib. On the other hand, the heat transfer coefficient is relatively lower for $\mathrm{h} / \mathrm{e}=0$ on the downstream side of the rib as compared to all other configurations. This can be due to relatively lower levels of turbulence induced in the airflow on the downstream side as in Figure 10(b), which can be due to lower levels of flow disturbance created by the rib configuration of $\mathrm{h} / \mathrm{e}=0$ owing to its geometry which is effectively a scalene triangle with finely sloped surfaces on either side of the rib. However, the turbulence intensity is relatively higher for the case of $\mathrm{h} / \mathrm{e}=0.25$ on the downstream side, as seen in Figure 10(b), owing to increased levels of flow disturbance caused by the rib. This can be due to the presence of flow impingement effect, which causes the main flow and the flow coming off the tip of the rib to interact, thereby causing flow mixing and increased energy transfer.

In addition, the heat transfer coefficient on the upstream side of the rib for $\mathrm{h} / \mathrm{e}=0.25$ is closer to that of $\mathrm{h} / \mathrm{e}=0$ and also exhibits the spike in heat transfer coefficient on the vertical rib surface due to flow impact effect. Thus, the rib configuration of $\mathrm{h} / \mathrm{e}=0.25$ produces greater heat transfer as compared to that of $\mathrm{h} / \mathrm{e}=0,0.5$ and 0.75 for a given rib angle of $15^{\circ}$. Interestingly, a comparison of Figure7(a) and Figure7(b) shows that the influence of approach length diminishes as the rib angle increases to $45^{\circ}$ due to the formation of recirculation zone and hot spots for all $\mathrm{h} / \mathrm{e}$ values and there are insignificant differences in the heat transfer augmentation brought in by the resulting flow structure. This is due to the fact that, as both rib angle and approach length increases, the resulting rib geometry will approach the geometry of $90^{\circ}$ rib angle and exhibits closer values of Nusselt number. For the rib angle of $90^{\circ}$, all the values of approach length lead to the same configuration of a right angled triangle rib as shown in Figure 7(c). Therefore, for higher rib angle the variation of non-dimensional approach length has negligible effect.

\section{Friction Factor Characteristics}

Figure 11 shows the variation of friction factor for a given approach length and different rib angles of $15^{\circ}, 45^{\circ}$ and $90^{\circ}$. The friction factor is clearly higher in the presence of ribs as compared to smooth duct owing to the increased flow resistance. The friction factor for smooth duct is determined by using the well-known modified Blasius equation [54] given by Eq. (15), and for duct with ribs is determined using Eq. (16).

$$
\begin{gathered}
f_{s}=0.085 R e^{-0.25} \\
f_{r}=\frac{\Delta p D_{h}}{2 \rho V^{2} L}
\end{gathered}
$$

From Figure 11(b), it is seen that for a given approach length of 0.25 , the rib angle of $15^{\circ}$ exhibits a lower friction factor while the rib angle of $90^{\circ}$ has a relatively higher friction factor. This is due to a relatively lower pressure drop across the ribs for lower rib angle, as shown in Figure 12. For the rib angle of $15^{\circ}$, the rib upstream surface is well aligned with the incoming airflow, which experiences lower impact as it strikes the inclined rib upstream surface. Thus, lower rib angle provides lower levels of flow obstruction and hence the pressure drop across the ribs are relatively lower as seen in Figure 12. As the rib angle increases towards $90^{\circ}$, the flow experiences increased impact on the rib upstream surface thereby causing increased flow obstruction and increases pressure drop across the ribs. Therefore, the friction factor increases with increasing rib angle, as seen in Figure11. Further from Figure 11(a) to Figure 11(d), it is observed that the effect of rib angle diminishes with increasing approach length. From Figure 11(a), for the case of h/e=0, since the resulting geometry is a scalene triangle with smooth surfaces on either side of the rib, the entire rib upstream surface is available 
for inclination. Thus, any variation of rib angle causes distinct changes in the flow and hence results in different levels of pressure drop across the rib. As the approach length changes from $\mathrm{h} / \mathrm{e}=0$ to $\mathrm{h} / \mathrm{e}=0.75$, the influence of rib angle on friction factor diminishes and all the rib angles exhibit friction factor values closer to that of rib angle of $90^{\circ}$. It may be noted that irrespective of the approach length, the rib angle of $90^{\circ}$ always leads to the geometry of the right-angled triangle rib. In addition, higher approach length and higher rib angle also makes the rib geometry approach that of the right-angled triangle geometry. Therefore, from Figure 11(a) to Figure 11(d), it can be clearly seen that as approach length increases from 0 to 0.75 , the friction factor for all the rib angles gets closer to that of $90^{\circ}$. Since the rib angle of $90^{\circ}$ exhibits the highest friction factor penalty, it can be therefore deduced that higher values of approach length and rib angle results in higher friction factor. The maximum friction factor is found to be about 1.62 times that of the smooth duct for the rib angle of $90^{\circ}$.

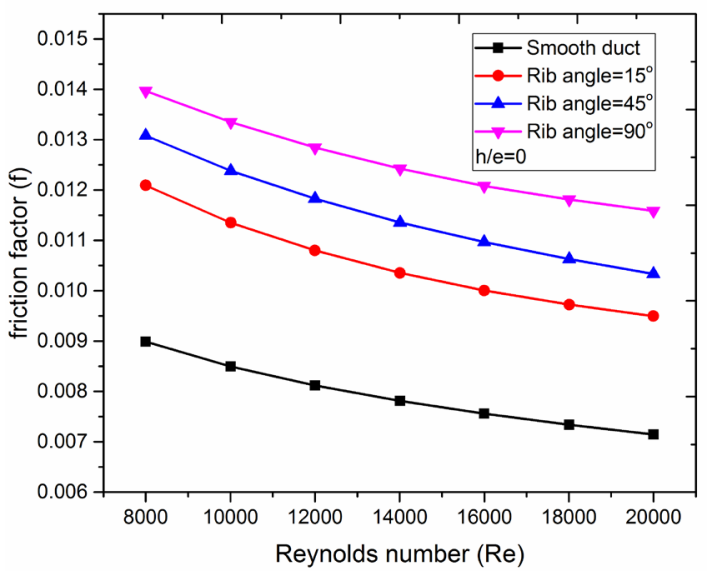

(a)

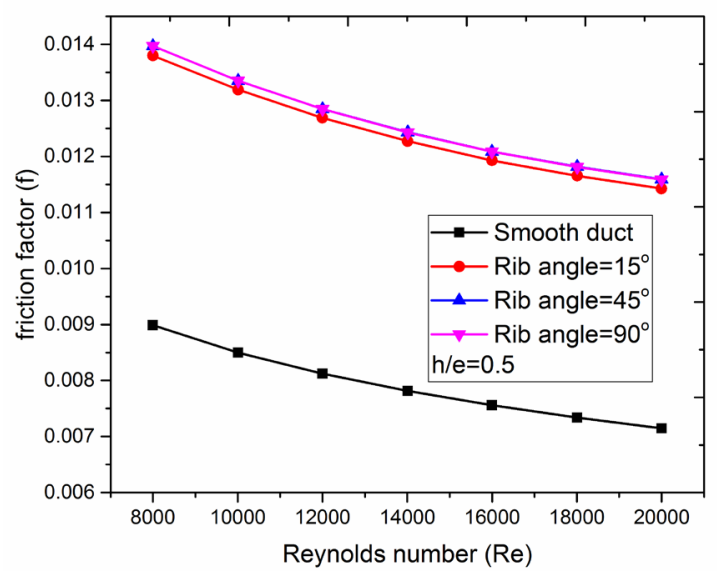

(c)

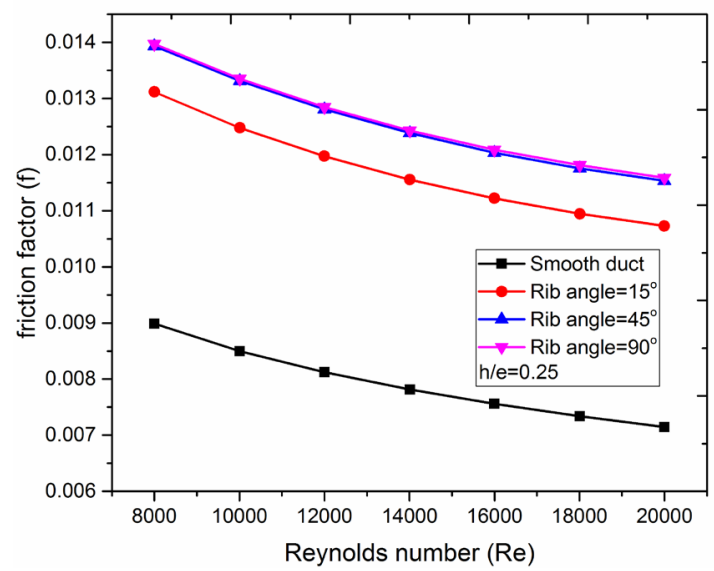

(b)

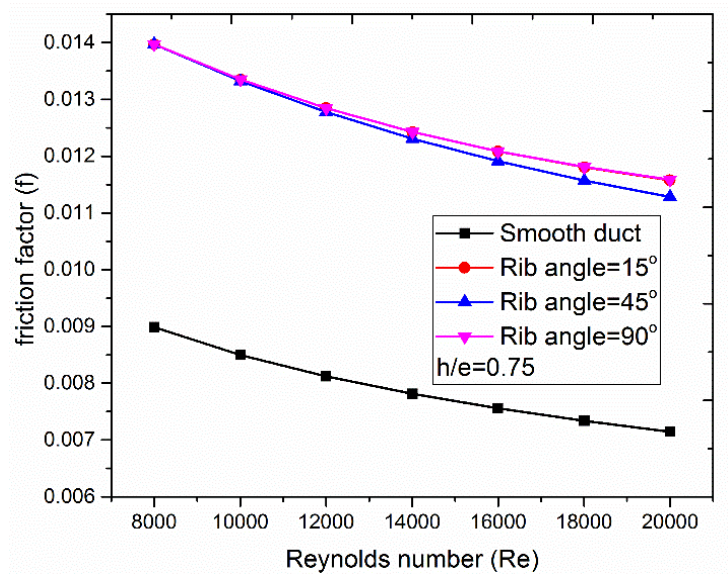

(d)

Figure 11. Influence of rib angle on the variation of friction factor for the non-dimensional approach length of (a) $\mathrm{h} / \mathrm{e}=0$ (b) $\mathrm{h} / \mathrm{e}=0.25$ (c) $\mathrm{h} / \mathrm{e}=0.5$ and (d) $\mathrm{h} / \mathrm{e}=0.75$

Figure 13 shows the influence of non-dimensional approach length on friction factor for a given rib angle. Figure 13(a) shows that the friction factor is higher for a higher approach length. This is due to the fact that the length of the upstream vertical rib surface increases with increasing approach length as a result of which much of the upstream surface receives the incoming air in a direction normal to it, causing increased flow obstruction. This is clearly seen in Figure 14, which shows a greater pressure drop across the rib at a higher approach length. The contour plots of pressure clearly show that at lower approach length, the impact of incoming air stream on the rib surface reduces due to which the pressure rise is relatively lower on the rib upstream surface. However, this effect increases with increasing approach length resulting in increased pressure drop across the ribs. From Figure 13 (a) to Figure 13(c), it can be seen that the difference in the friction factor among different approach length values decreases and approaches that of $90^{\circ}$ as higher approach length and rib angle always leads to a geometry that is closer to the geometry of $90^{\circ}$ rib angle. Thus, it can be deduced that lower rib angle provides a lower friction factor penalty and the effect of approach length variation is significant only at lower rib angles. 


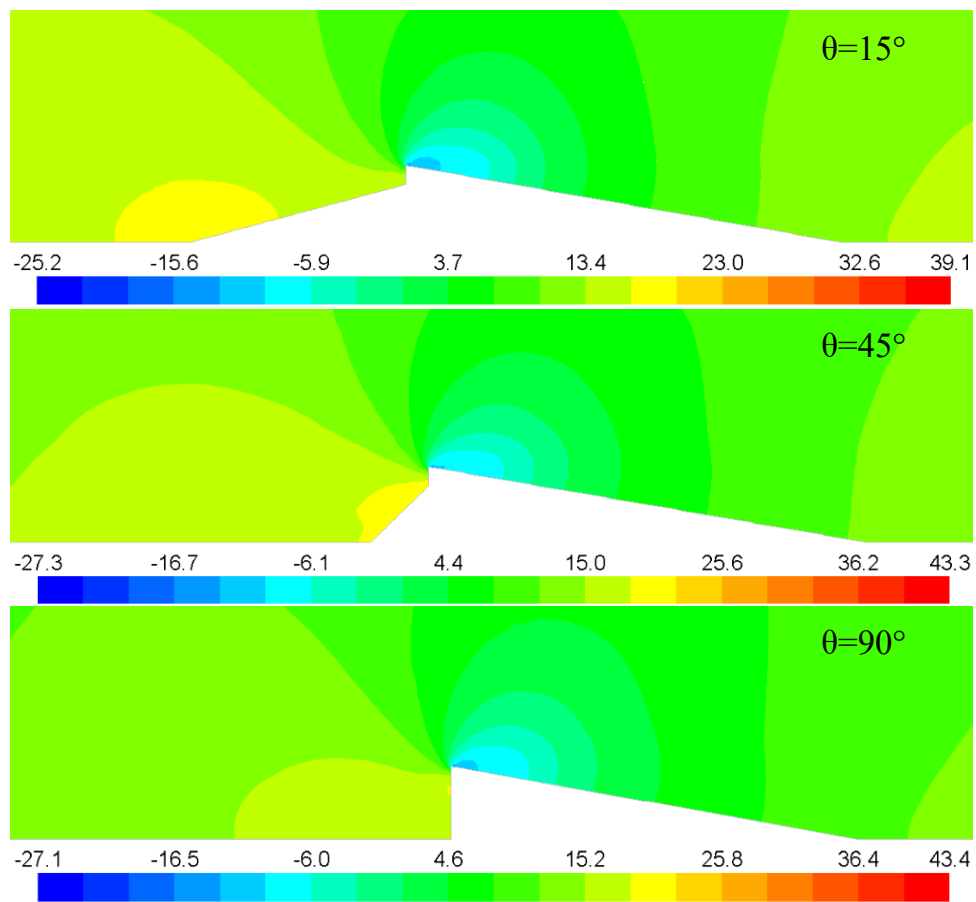

Figure 12. Comparison of pressure distribution in the airflow around the ribs for $\mathrm{h} / \mathrm{e}=0.25$ and different rib angles of $15^{\circ}, 45^{\circ}$ and $90^{\circ}$.

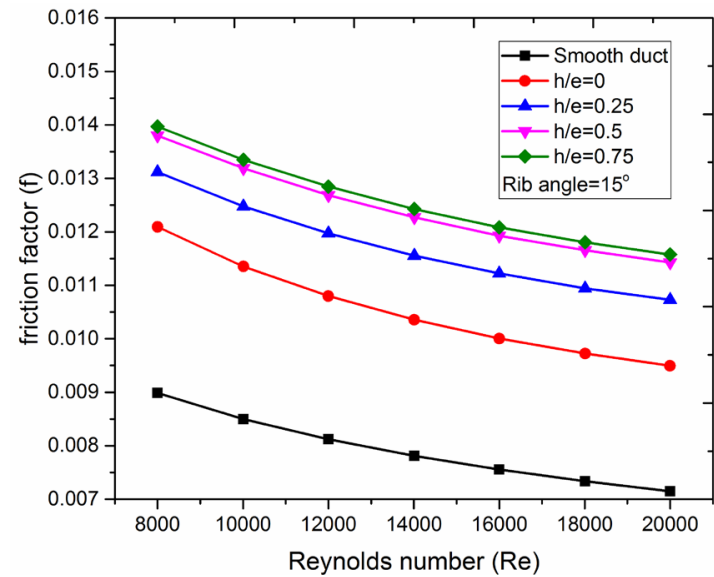

(a) $15^{\circ}$

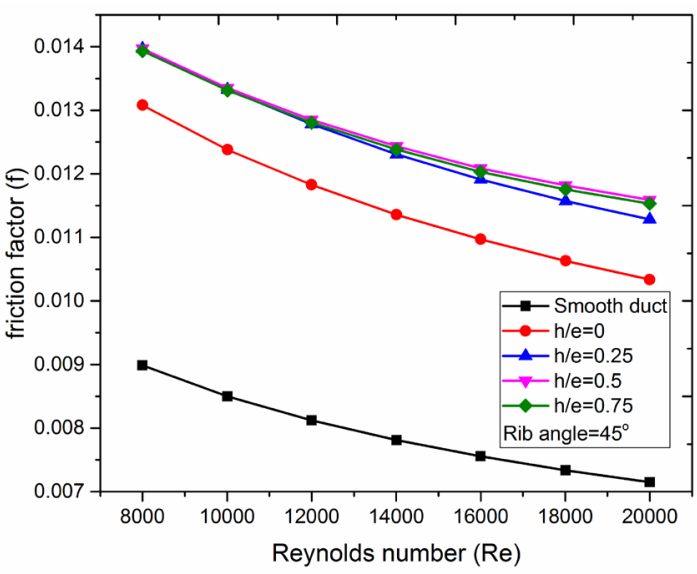

(b) $45^{\circ}$

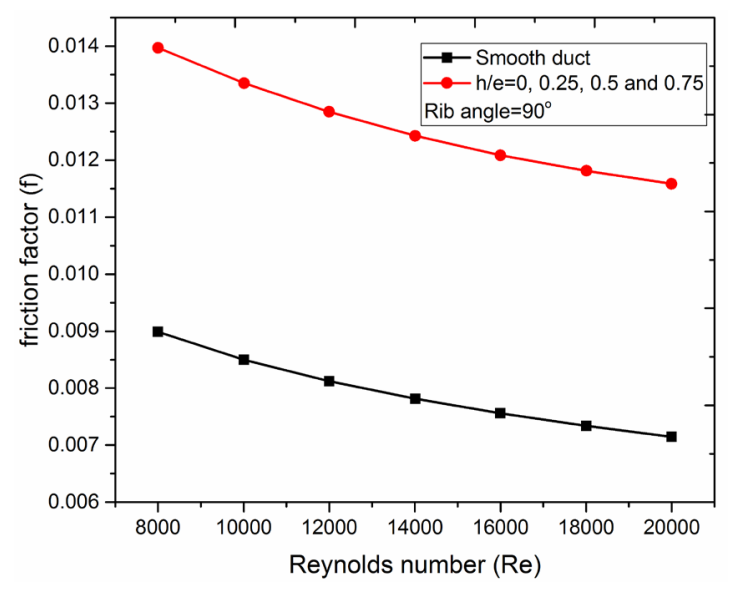

(c) $90^{\circ}$

Figure 13. Influence of non-dimensional approach length on the variation of friction factor for different rib angles.

Based on the numerical data, correlations of Nusselt number and friction factor have been developed in terms of geometric and flow parameters for the flow Reynolds number of 8000-20000. The correlation is developed following the process used by Bhagoria et al. [54]. The Nusselt number and friction factor are both seen to be strongly dependent on the rib angle, approach length and Reynolds number of the flow for a fixed relative pitch of $\mathrm{P} / \mathrm{e}=12.5$. The average deviation between the numerical data and data generated by correlations are found to be within $\pm 5 \%$ for both Nusselt 
number and friction factor as shown in Figure 15(a) and Figure 15(b), respectively. The correlations are given by the following equations.

$$
\begin{gathered}
N u=0.0835\left(\exp \left[0.01\left(\frac{h}{e}\right)\right]\right)\left(\theta^{0.012}\right) R e^{0.6999} \\
f=0.0855\left(\exp \left[0.1383\left(\frac{h}{e}\right)\right]\right)\left(\theta^{0.0363}\right) R e^{-0.224}
\end{gathered}
$$

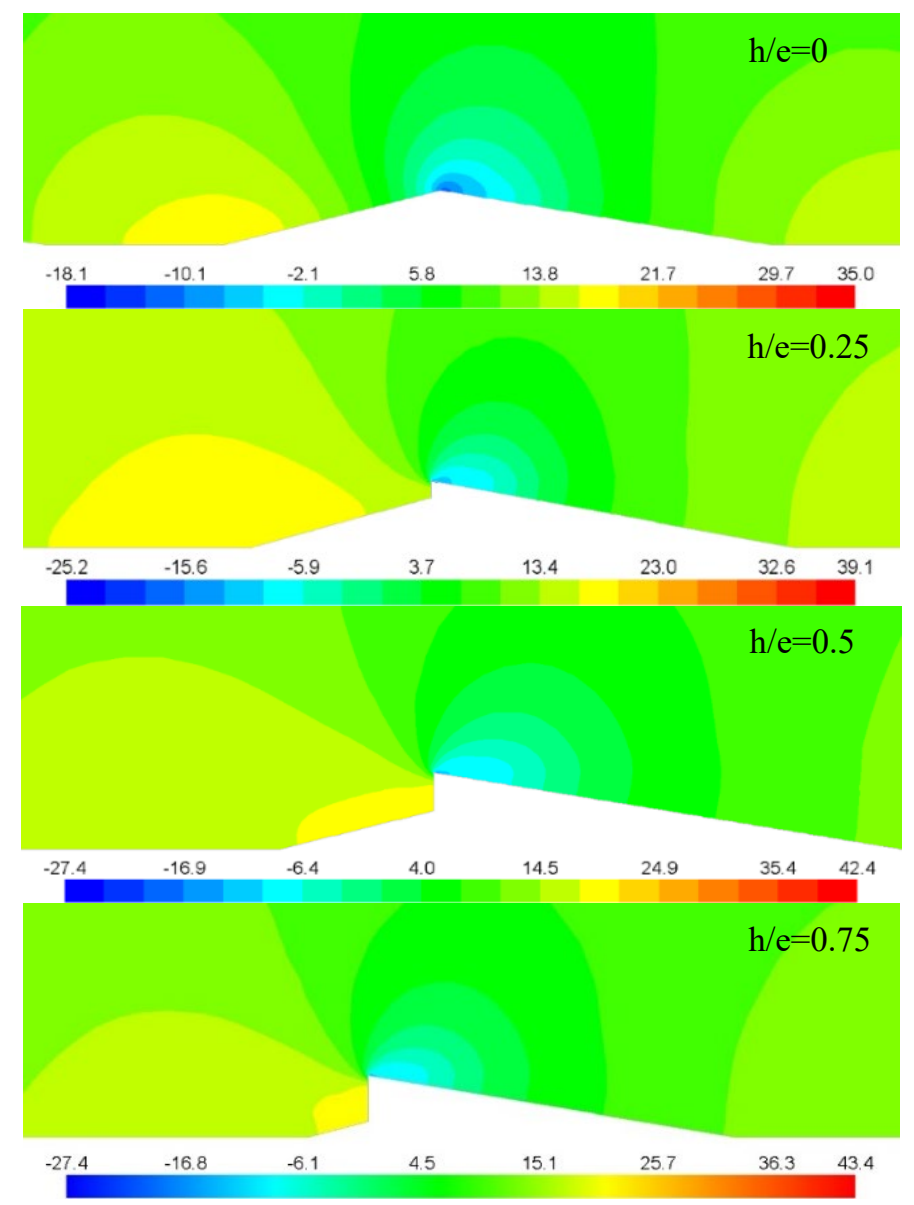

Figure 14. Comparison of pressure distribution in the airflow around the ribs for rib angle of $15^{\circ}$ and different nondimensional approach lengths $(\mathrm{h} / \mathrm{e})$ of $0,0.25,0.5$ and 0.75 .

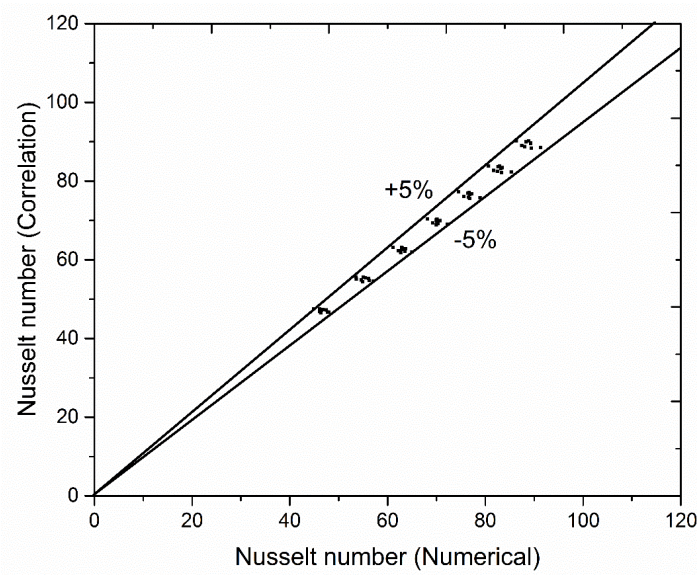

(a)

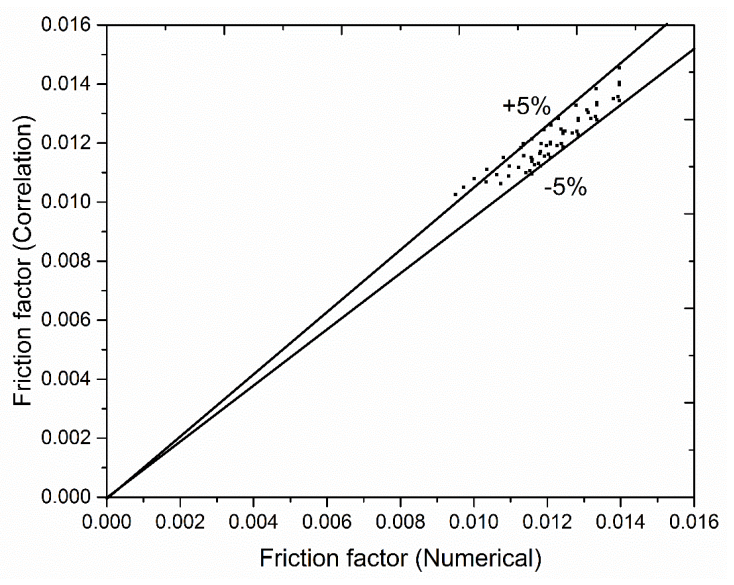

(b)

Figure15. Comparison of (a) Nusselt number (Numerical) with the predicted Nusselt number using correlation and (b) friction factor (Numerical) with the predicted friction factor using correlation. 


\section{Thermal Enhancement Factor}

The thermal enhancement factor (TEF) determines the actual usefulness of the rib for heat transfer enhancement by considering the combined effect of heat transfer augmentation and friction factor penalty. The thermal enhancement factor is determined by Eq. (19). The relative enhancement of heat transfer and friction factor becomes important in the calculation of TEF and is determined using Nusselt number enhancement ratio (NER) and friction factor enhancement ratio (FER) as given by Eq. (20) and Eq. (21), respectively.

$$
\begin{gathered}
T E F=\frac{\left(\frac{N u_{r}}{N u_{s}}\right)}{\left(\frac{f_{r}}{f_{s}}\right)^{\frac{1}{3}}} \\
N E R=\frac{N u_{r}}{N u_{s}} \\
\text { FER }=\frac{f_{r}}{f_{s}}
\end{gathered}
$$

The variation of NER and FER for the approach length of 0.25 and different rib angles of $15^{\circ}, 45^{\circ}$ and $90^{\circ}$ is shown in Figure 16(a). It is seen that the NER for the rib angle of $15^{\circ}$ is the highest, while the corresponding FER is the lowest among the three rib angles used in the study. It is noted that the NER is higher for the lower rib angle, while the FER exhibits a reverse trend where lower rib angles have a lower friction factor penalty. As a result of relatively higher NER with a corresponding lower FER, the TEF is higher for lower rib angles, as shown in Figure17(a). The maximum TEF is found to have a range of 1.6-1.45 for the rib configuration having $\mathrm{h} / \mathrm{e}=0.25$ and rib angle of $15^{\circ}$.

Figure 16(b) shows the variation of NER and FER for the rib angle of $15^{\circ}$ and different approach lengths. It is seen that the NER increases as the approach length increases from $\mathrm{h} / \mathrm{e}=0$ to $\mathrm{h} / \mathrm{e}=0.25$ and decreases thereafter and follows the same trend of Nusselt number variation. However, the FER increases with increasing values of approach length as seen in Figure 16(b) owing to the fact that the flow obstruction is greater at higher approach length of the rib resulting in increased friction factor penalty. The rib configuration having greater approach length values of 0.5 and 0.75 have higher FER and also exhibit lower levels of NER. Therefore, the TEF for the rib configuration having the non-dimensional approach length of 0.5 and 0.75 is relatively lower as seen in Figure 17(b). The rib configuration having h/e=0 exhibits lower NER as seen in Figure 16(b), but it has the lowest FER as the ribs offer lower levels of flow obstruction, thereby reducing the friction factor penalty. Hence, the TEF for this rib configuration is at a higher level, as seen in Figure 17(b). The TEF varies between $1.58-1.48$ and performs very close to that of the rib having $\mathrm{h} / \mathrm{e}=0.25$. It is interesting to note that the TEF for the rib having $\mathrm{h} / \mathrm{e}=0.25$ is higher than that of $\mathrm{h} / \mathrm{e}=0$ for the Reynolds number limit of 13000 beyond, which it drops relative to the rib configuration having $\mathrm{h} / \mathrm{e}=0$. Thus, it can be deduced that for a given rib angle, a lower approach length provides a higher thermal enhancement factor.

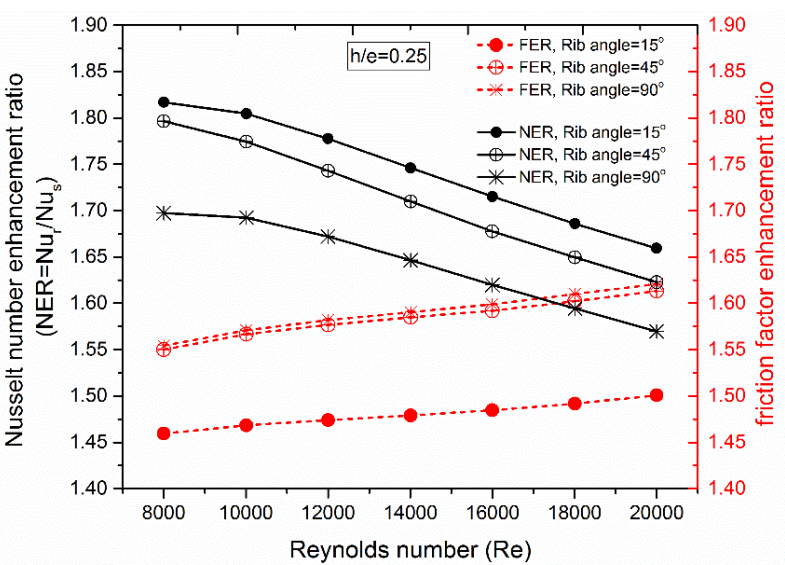

(a)

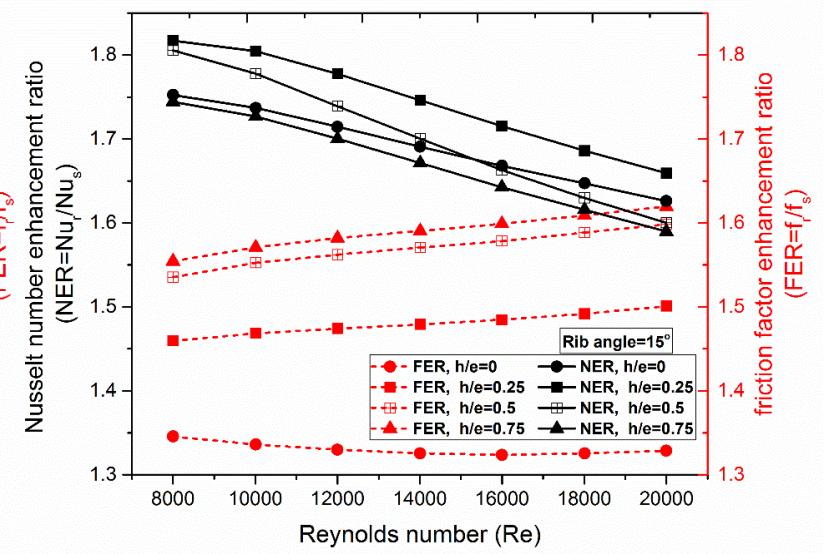

(b)

Figure 16. Comparison of Nusselt number enhancement ratio and friction factor enhancement ratio for (a) $h / e=0.25$ and different rib angles of $15^{\circ}, 45^{\circ}$ and $90^{\circ}$, and (b) rib angle of $15^{\circ}$ and different non-dimensional approach length $(\mathrm{h} / \mathrm{e})$ of $0,0.25,0.5$ and 0.75 . 


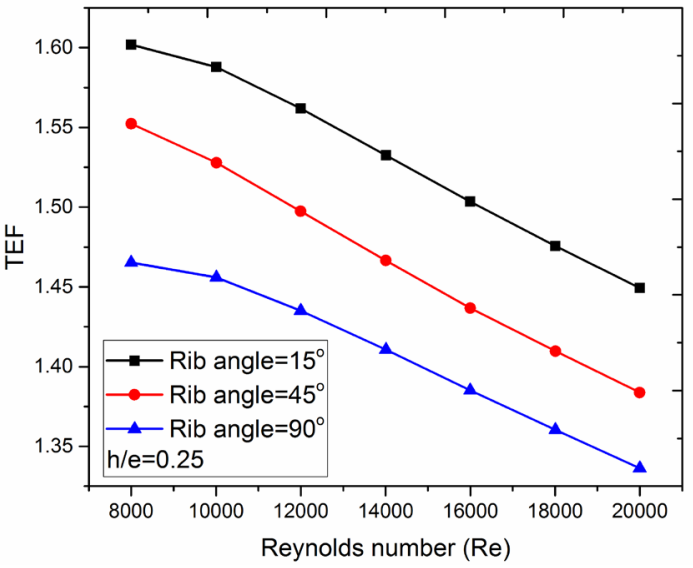

(a)

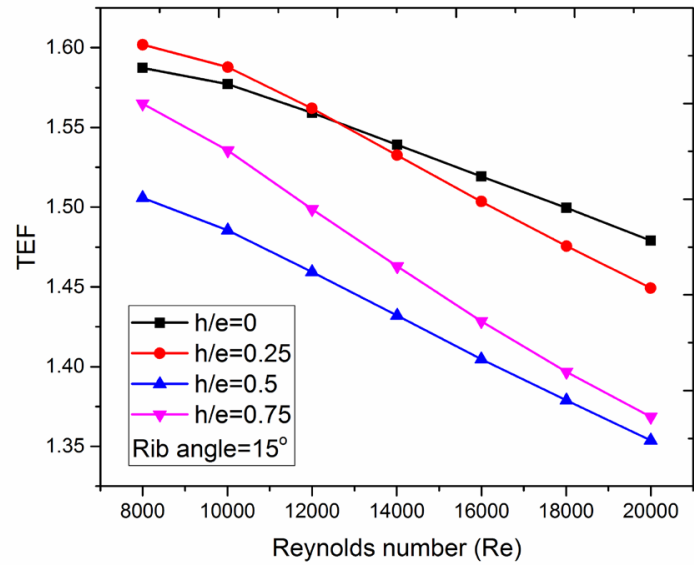

(b)

Figure 17. Thermal enhancement factor for (a) $\mathrm{h} / \mathrm{e}=0.25$ and different rib angles of $15^{\circ}, 45^{\circ}$ and $90^{\circ}$, (b) rib angle of $15^{\circ}$ and different non-dimensional approach length $(\mathrm{h} / \mathrm{e})$ of $0,0.25,0.5$ and 0.75 .

Table 4 shows the comparison of Nusselt number enhancement (NER) and friction factor enhancement (FER) for various rib geometries used in the literature. The results are seen to be better than pentagonal and compound ribs in terms of both heat transfer and friction factor. It is noted that the maximum friction factor enhancement obtained from the present study is significantly lower than most of the rib geometries used in the literature.

Table 4. Comparison of the present study with published works.

\begin{tabular}{|c|c|c|c|}
\hline Rib geometry & $\begin{array}{l}\text { Maximum } \\
\text { NER }\end{array}$ & $\begin{array}{l}\text { Maximum } \\
\text { FER }\end{array}$ & Range of Parameters used in the analysis \\
\hline Pentagonal ribs [11] & 1.7 & 1.67 & $\mathrm{Re}=12633-38414, \mathrm{e} / \mathrm{D}=0.045-0.084, \mathrm{P} / \mathrm{e}=6.43-8$ \\
\hline Inclined discrete ribs [15] & 2.83 & 3.6 & $\begin{array}{c}\mathrm{Re}=3000-18000, \text { non-dimensional width }=5.83, \text { attack } \\
\text { angle }=30^{\circ}-90^{\circ}, \mathrm{p} / \mathrm{e}=4-10\end{array}$ \\
\hline Multi-V shaped rib [17] & 3.81 & 10.57 & $\mathrm{Re}=8000-20000$, width ratio $=3-8$, attack angle $=30^{\circ}-75^{\circ}$ \\
\hline W-shaped ribs [18] & 2.36 & 2.01 & $\begin{array}{c}\mathrm{Re}=2300-14000, \text { attack angle }=30^{\circ}-75^{\circ}, \mathrm{e}=0.018- \\
0.03375, \mathrm{P} / \mathrm{e}=10\end{array}$ \\
\hline Multiple broken ribs [27] & 2.5 & 3.92 & $\mathrm{Re}=3000-18000, \mathrm{P} / \mathrm{e}=10, \mathrm{e} / \mathrm{D}=0.043$ \\
\hline $\begin{array}{l}\text { Non-uniform cross-section } \\
\text { transverse rib [29] }\end{array}$ & 2.18 & 3.34 & $\begin{array}{c}\mathrm{Re}=3000-15000, \mathrm{P} / \mathrm{e}=4-30, \mathrm{e} / \mathrm{D}=0.043, \text { attack } \\
\text { angle }=45^{\circ}\end{array}$ \\
\hline Rectangular rib [34] & 2.7 & 4.5 & $\mathrm{Re}=4000-18000, \mathrm{e} / \mathrm{D}=0.04, \mathrm{P} / \mathrm{e}=5-15$ \\
\hline Square rib [43] & 2.86 & 3.83 & $\mathrm{Re}=3800-18000, \mathrm{e} / \mathrm{D}=0.021-0.042, \mathrm{P} / \mathrm{e}=10.71$ \\
\hline $\begin{array}{l}\text { Equilateral triangular rib } \\
\text { [45] }\end{array}$ & 3.073 & 3.356 & $\mathrm{Re}=3800-18000, \mathrm{e} / \mathrm{D}=0.021-0.042, \mathrm{P} / \mathrm{e}=7.14-35.71$ \\
\hline Circular rib [46] & 2.31 & 3.14 & $\mathrm{Re}=3800-18000, \mathrm{e} / \mathrm{D}=0.021-0.042, \mathrm{P} / \mathrm{e}=7.14-35.71$ \\
\hline NACA $0040 \mathrm{rib}$ [49] & 2.95 & 2.42 & $\mathrm{Re}=6000-18000, \mathrm{P} / \mathrm{e}=5, \mathrm{e} / \mathrm{D}=0.065$ \\
\hline Compound rib [51] & 1.29 & 1.38 & $\mathrm{Re}=4000-15000, \mathrm{e} / \mathrm{D}=0.02-0.045, \mathrm{P} / \mathrm{e}=6-16$ \\
\hline Present work & 1.82 & 1.62 & $\begin{array}{c}\mathrm{Re}=8000-20000, \text { non-dimensional approach length }=0- \\
\quad 0.75, \mathrm{P} / \mathrm{e}=12.5, \mathrm{e} / \mathrm{D}=0.0421, \mathrm{rib} \text { angle }=30^{\circ}-90^{\circ}\end{array}$ \\
\hline
\end{tabular}

\section{CONCLUSION}

Formation of recirculation zones on the transverse rib corners impede heat transfer and the use of angled rib surfaces on the downstream rib side only partially overcomes this limitation. Entrapped recirculation zones are formed on the upstream side of the ribs as well, which affects the heat transfer considerably and cannot be resolved by merely providing an angled rib surface. This paper presents a detailed two-dimensional numerical analysis to determine the influence of rib upstream surface modifications on the overall thermal performance of a novel clerestory shaped rib that is transversely placed in the heating section. The upstream surface is divided into two parts where the upper part is always normal to the flow while the bottom part is inclined to the incoming flow. The inclination of the bottom rib surface is defined using the rib angle, which is varied as $15^{\circ}, 45^{\circ}$ and $90^{\circ}$ whereas the upper vertical rib surface is varied in its height using the nondimensional approach length as $0,0.25,0.5$ and 0.75 . The analysis is carried out for the Reynolds number range of 8000 20000 using RNG k-€ turbulence model. The performance parameters such as Nusselt number, friction factor and the overall thermal performance parameter such as thermal enhancement factor is made use of to bring out the efficacy of the proposed rib modifications. The following are the major conclusions from the analysis:

i. The combined effect of flow impingement and the suppression of formation of recirculation zone leads to increased heat transfer. 
ii. For a given non-dimensional approach length, a lower rib angle produces greater heat transfer augmentation.

iii. For a given rib angle, an approach length of 0.25 produces greater heat transfer augmentation.

iv. The highest increase in Nusselt number is found to be about 1.82 times that of smooth duct at $\mathrm{Re}=8000$ for the approach length of 0.25 and rib angle of $15^{\circ}$.

v. For higher rib angles, the variation of non-dimensional approach length has a negligible effect.

vi. The use of higher non-dimensional approach length and rib angle results in a higher friction factor penalty.

vii. The maximum friction factor is found to be about 1.62 times that of the smooth duct for the rib angle of $90^{\circ}$ at $\mathrm{Re}=20000$.

viii. The lowest friction factor is exhibited by the rib configuration having $\mathrm{h} / \mathrm{e}=0$ and rib angle of $15^{\circ}$.

ix. For a given rib approach length, lower rib angles produce higher TEF.

x. For a given rib angle, lower values of non-dimensional approach length provide a higher thermal enhancement factor.

xi. The maximum TEF is found to have a range of 1.6-1.45 for the rib configuration having $\mathrm{h} / \mathrm{e}=0.25$ and $\mathrm{rib}$ angle of $15^{\circ}$.

\section{ACKNOWLEDGEMENT}

The authors express their gratitude to the Department of Mechanical and Manufacturing Engineering, Manipal Institute of Technology, Manipal, MAHE, for providing the computational facilities to carry out the research work. This work did not receive any external funding and the authors declare no conflict of interest in this research work.

\section{REFERENCES}

[1] D. Jain, "Modeling the system performance of multi-tray crop drying using an inclined multi-pass solar air heater with in-built thermal storage," J Food Eng., 2005, vol. 71, no. 1, p. 44-54, doi: 10.1016/j.jfoodeng.2004.10.016.

[2] C.K.K. Sekyere et al., "Mathematical modelling and validation of the thermal buoyancy characteristics of a mixed mode natural convection solar crop dryer with back up heater," Sci African, 2020, no. 8, doi: 10.1016/j.sciaf.2020.e00441.

[3] S. Lahsasni et al., "Thin layer convective solar drying and mathematical modeling of prickly pear peel (Opuntia ficus indica)," Energy, 2004, vol. 29, no. 2, p. 211-24, doi: 10.1016/j.energy.2003.08.009.

[4] P. Mehta et al., "Design and performance analysis of a mixed mode tent-type solar dryer for fish-drying in coastal areas," Sol Energy, 2018, vol. 170, May, p. 671-81, doi: 10.1016/j.solener.2018.05.095.

[5] H. Akhan, and D. Eryener, 'Building integrated solar air heating with waste heat utilization,' Energy Convers Manag. , 2018, vol. 157, October 2017, p. 136-45, doi: 10.1016/j.enconman.2017.12.007. [Accessed: October 2017].

[6] Z. Ma, H. Ren, and W. Lin, "A review of heating, ventilation and air conditioning technologies and innovations used in solarpowered net zero energy Solar Decathlon houses," J Clean Prod., 2019, vol. 240, doi: 10.1016/j.jclepro.2019.118158

[7] A. Khanlari et al., "Drying municipal sewage sludge with v-groove triple-pass and quadruple-pass solar air heaters along with testing of a solar absorber drying chamber," Sci Total Environ., 2020, vol. 709, doi: 10.1016/j.scitotenv.2019.136198.

[8] F.R. Siddiqui, N.A.S. Elminshawy, and M.F. Addas, "Design and performance improvement of a solar desalination system by using solar air heater: Experimental and theoretical approach," Desalination, 2016, vol. 399, p. 78-87, doi: 10.1016/j.desal.2016.08.015

[9] B.N. Prasad and J.S. Saini, “Optimal thermohydraulic performance,” Sol Energy, 1991, vol. 47, no. 2, p. 91-6.

[10] V.B Gawande et al., "A review of CFD methodology used in literature for predicting thermo-hydraulic performance of a roughened solar air heater," Renew Sustain Energy Rev., 2016, vol. 54, p. 550-605, doi: 10.1016/j.rser.2015.10.025

[11] S. Debnath, B. Das, and P. Randive, "Influences of pentagonal ribs on the performance of rectangular solar air collector," Energy Procedia, 2019, vol. 158, p. 1168-73, doi: 10.1016/j.egypro.2019.01.300.

[12] M.A. Moon, M.J. Park, and K.Y. Kim, "Evaluation of heat transfer performances of various rib shapes," Int J Heat Mass Transf., 2014, vol. 71, p. 275-84, doi: 10.1016/j.ijheatmasstransfer.2013.12.026.

[13] A.J. Nowak, "Computation of flow and heat transfer in two-dimensional rib-roughened passages using low-Reynolds-number turbulence models," Int J Numer. Methods Heat Fluid Flow, vol. 24, no. 4, pp. 138-155, 2001, doi: 10.1108/09615530110381566.

[14] C. Sivakandhan, T.V. Arjunan, and M.M. Matheswaran, "Thermohydraulic performance enhancement of a new hybrid duct solar air heater with inclined rib roughness. Renew energy, 2020, vol. 147, p. 2345-2357, doi: 10.1016/j.renene.2019.10.007.

[15] K.R. Aharwal, B.K. Gandhi, and J.S. Saini, "Heat transfer and friction characteristics of solar air heater ducts having integral inclined discrete ribs on absorber plate," Int J Heat Mass Transf., 2009, vol. 52, no. 25-26, p. 5970-5977, doi: 10.1016/j.ijheatmasstransfer.2009.05.032.

[16] R. Kumar et al., "Performance evaluation and optimization of solar assisted air heater with discrete multiple arc shaped ribs," J Energy Storage, 2019, vol. 26, December, doi: 10.1016/j.est.2019.100978.

[17] D. Jin et al., "Numerical investigation of heat transfer and fluid flow in a solar air heater duct with multi V-shaped ribs on the absorber plate," energy, 2015, vol. 89, p. 178-190, doi: 10.1016/j.energy.2015.07.069.

[18] A. Lanjewar, J.L. Bhagoria, and R.M. Sarviya, "Heat transfer and friction in solar air heater duct with W-shaped rib roughness on absorber plate," energy, 2011, vol. 36, no. 7, p. 4531-4541, doi: 10.1016/j.energy.2011.03.054. 
[19] P.J. Bezbaruah, R.S. Das, and B.K. Sarkar, "Overall performance analysis and GRA optimization of solar air heater with truncated half conical vortex generators," Sol Energy, 2020, vol. 196, p. 637-652, doi: 10.1016/j.solener.2019.12.057.

[20] A.L. Antony et al., "Vasudeva Karanth K. Influence of stepped cylindrical turbulence generators on the thermal enhancement factor of a flat plate solar air heater," Sol Energy, 2020, vol. 198, p. 295-310, doi: 10.1016/j.solener.2020.01.065.

[21] M.S. Manjunath, K.V. Karanth, and N.Y. Sharma, "Numerical analysis of the influence of spherical turbulence generators on heat transfer enhancement of flat plate solar air heater," energy, 2017, vol. 121, January, p. 616-630, doi: 10.1016/j.energy.2017.01.032.

[22] R.P. Saini and J. Verma, "Heat transfer and friction factor correlations for a duct having dimple-shape artificial roughness for solar air heaters," Energy, 2008, vol. 33, no. 8, p. 1277-1287, doi: 10.1016/j.energy.2008.02.017.

[23] M. Sethi, G. Varun, and NS. Thakur, "Correlations for solar air heater duct with dimpled shape roughness elements on absorber plate," Sol Energy, 2012, vol. 86, no. 9, p. 2852-2861, doi: 10.1016/j.solener.2012.06.024.

[24] A. Kumar, and A. Layek, "Nusselt number and friction factor correlation of solar air heater having winglet type vortex generator over absorber plate," Sol Energy, 2020, vol. 205, April, p. 334-348, doi: 10.1016/j.solener.2020.05.047.

[25] D.J Dezan, A.D. Rocha, and W.G. Ferreira, "Parametric sensitivity analysis and optimisation of a solar air heater with multiple rows of longitudinal vortex generators," Appl Energy, 2020, vol. 263, January, doi: 10.1016/j.apenergy.2020.114556.

[26] A. Kumar, and A. Layek, "Nusselt number and fluid flow analysis of solar air heater having transverse circular rib roughness on absorber plate using LCT and computational technique," Therm Sci Eng Prog, 2019, vol. 14, August, doi: 10.1016/j.tsep.2019.100398.

[27] I. Singh, S. Vardhan, S. Singh, and A. Singh, "Experimental and CFD analysis of solar air heater duct roughened with multiple broken transverse ribs: A comparative study," Sol Energy, 2019, vol. 188, April, p. 519-532, doi: 10.1016/j.solener.2019.06.022.

[28] R. Karwa, S.C. Solanki, and J.S. Saini, "Heat transfer coefficient and friction factor correlations for the transitional flow regime in rib-roughened rectangular ducts," Int J Heat Mass Transf., 1999, vol. 42, no. 9, p. 1597-1615, doi: 10.1016/S00179310(98)00252-X.

[29] A. Singh, and S. Singh, "CFD investigation on roughness pitch variation in non-uniform cross-section transverse rib roughness on Nusselt number and friction factor characteristics of solar air heater duct," energy, 2017, vol. 128, p. 109-127, doi: 10.1016/j.energy.2017.04.008.

[30] S. Singh et al., "CFD (computational fluid dynamics) investigation on Nusselt number and friction factor of solar air heater duct roughened with non-uniform cross-section transverse rib," energy, 2015, vol. 84, p. 509-517, doi: 10.1016/j.energy.2015.03.015.

[31] G. Kumar et al., "Experimental investigation on heat transfer augmentation of solar air heater using shot blasted V-corrugated absorber plat," Renew energy, 2018, vol. 127, p. 213-229, doi: 10.1016/j.renene.2018.04.056.

[32] M.S. Manjunath, K.V. Karanth, and N.Y. Sharma, "Numerical investigation on heat transfer enhancement of solar air heater using sinusoidal corrugations on absorber plate," Int J Mech Sci.. 2018, vol. 138-139, January, p. 219-28, doi: 10.1016/j.ijmecsci.2018.01.037.

[33] S. Skullong et al., "Thermal performance of turbulent flow in a solar air heater channel with rib-groove turbulators," Int Commun Heat Mass Transf., 2014, vol. 50, p. 34-43, doi: 10.1016/j.icheatmasstransfer.2013.11.001.

[34] R. Kumar, A. Kumar, and V. Goel, "A parametric analysis of rectangular rib roughened triangular duct solar air heater using computational fluid dynamics," Sol Energy, 2017, vol. 57, February, p. 1095-1107, doi: 10.1016/j.solener.2017.08.071.

[35] S. Singh, "Thermal performance analysis of semicircular and triangular cross-sectioned duct solar air heaters under external recycle," J Energy Storage, 2018, vol. 20, October, p. 316-336, doi: 10.1016/j.est.2018.10.003.

[36] K. Nidhul et al., "Enhanced thermo-hydraulic performance in a V-ribbed triangular duct solar air heater: CFD and exergy analysis," energy, 2020, vol. 200, Available from: 10.1016/j.energy.2020.117448.

[37] K. Nidhul et al., "Efficient design of an artificially roughened solar air heater with semi-cylindrical side walls: CFD and exergy analysis," Sol Energy, 2020, 207, April, p. 289-304, doi: 10.1016/j.solener.2020.06.054.

[38] V.B Gawande, A.S. Dhoble, and D.B. Zodpe, "Effect of roughness geometries on heat transfer enhancement in solar thermal systems - A review," Renew Sustain Energy Rev., 2014, vol. 32, p. 347-378, doi: 10.1016/j.rser.2014.01.024.

[39] T. Alam, and M.H. Kim, "A critical review on artificial roughness provided in rectangular solar air heater duct," Renew Sustain Energy Rev., 2017, vol. 69, p. 387-400, doi: 10.1016/j.rser.2016.11.192.

[40] I. Singh, and S. Singh, “A review of artificial roughness geometries employed in solar air heaters," Renew Sustain Energy Rev. 2018, vol. 92, May, p. 405-425, doi: 10.1016/j.rser.2018.04.108.

[41] G.K. Chhaparwal, A. Srivastava, and R. Dayal, "Artificial repeated-rib roughness in a solar air heater - A review," Sol Energy, 2019, vol. 194, August, p. 329-359, doi: 10.1016/j.solener.2019.10.011.

[42] A. Singh Yadav and M. Kumar Thapak, "Artificially roughened solar air heater: Experimental investigations," Renew Sustain Energy Rev., 2014, vol. 36, p. 370-411, doi: 10.1016/j.rser.2014.04.077.

[43] A.S. Yadav, and JL Bhagoria, "A numerical investigation of square sectioned transverse rib roughened solar air heater," Int $J$ Therm Sci ., 2014, vol. 9, p. 111-31, doi: 10.1016/j.jithermalsci.2014.01.008.

[44] A. Boulemtafes-Boukadoum and A. Benzaoui, "CFD based analysis of heat transfer enhancement in solar air heater provided with transverse rectangular ribs,” Energy Procedia, 2014, vol. 50, p. 761-772, doi: 10.1016/j.egypro.2014.06.094. 
[45] A.S. Yadav, and JL Bhagoria, "A CFD based thermo-hydraulic performance analysis of an artificially roughened solar air heater having equilateral triangular sectioned rib roughness on the absorber plate," Int J Heat Mass Transf., 2014, vol. 70, p. 1016-1039, doi: 10.1016/j.ijheatmasstransfer.2013.11.074.

[46] A.S. Yadav, and JL Bhagoria, "A CFD (computational fluid dynamics) based heat transfer and fluid flow analysis of a solar air heater provided with circular transverse wire rib roughness on the absorber plate," energy, 2013, vol. 55, p. 1127-1142, doi: 10.1016/j.energy.2013.03.066.

[47] D. Gupta, SC. Solanki, and J.S. Saini, "Heat and fluid flow in rectangular solar air heater ducts having transverse rib roughness on absorber plates," Sol. Energy, 1993, vol. 51, no. 1, p. 31-37, doi: 10.1016/0038-092X(93)90039-Q.

[48] R. Kumar, V. Geol, and A. Kumar, "A parametric study of the 2D model of solar air heater with elliptical rib roughness using CFD,” J Mech Sci Technol., 2017, vol. 31, no. 2, p. 959-964, doi: 10.1007/s12206-017-0148-7.

[49] Y.M. Patel, S. V. Jain, and V.J. Lakhera, "Thermo-hydraulic performance analysis of a solar air heater roughened with reverse NACA profile ribs," Appl Therm Eng., 2020, vol. 70, January, doi: 10.1016/j.applthermaleng.2020.114940.

[50] Y. Mahanand, A. Mahato, and D.S. Khamari, “CFD Analysis of Semi-Circular Rib Roughened Solar Air Heater," Int J Adv Mech Eng., 2018, vol. 8, no. 1, p. 251-262.

[51] A. Chaube, P.K. Sahoo, and S.C. Solanki, "Analysis of heat transfer augmentation and flow characteristics due to rib roughness over absorber plate of a solar air heater," Renewable Energy, 2006, vol. 31, no. 3, p. 317-331, doi: 10.1016/j.renene.2005.01.012.

[52] A. Layek, J.S. Saini, and S.C. Solanki, "Effect of chamfering on heat transfer and friction characteristics of solar air heater having absorber plate roughened with compound turbulators," Renew Energy, 2009, vol. 34, no. 5, p. 1292 1298, doi: 10.1016/j.renene.2008.09.016.

[53] R. Kumar, V. Goel, and A. Kumar, "Investigation of heat transfer augmentation and friction factor in triangular duct solar air heater due to forward facing chamfered rectangular ribs: A CFD based analysis," Renew Energy, 2018, vol. 115, p. 824-835, doi: 10.1016/j.renene.2017.09.010.

[54] J.L Bhagoria, J.S. Saini, and S.C. Solanki, "Heat transfer coefficient and friction factor correlations for rectangular solar air heater duct having transverse wedge shaped rib roughness on the absorber plate," Renew energy, 2002, vol. 25, no. 3, p. 341369, doi: 10.1016/S0960-1481(01)00057-X.

[55] A.Z. Aghaie, A.B. Rahimi, and A. Akbarzadeh, "A general optimized geometry of angled ribs for enhancing the thermohydraulic behavior of a solar air heater channel - A Taguchi approach," Renew Energy, 2015, vol. 83, p. 47-54, doi: 10.1016/j.renene.2015.04.016.

[56] C. Min et al., "Inverse simulation to optimize the rib-profile in a rectangular flow-channel," Int Commun Heat Mass Transf., 2020, vol. 114, April, doi: 10.1016/j.icheatmasstransfer.2020.104567.

[57] M.S. Manjunath R. Venkatesh, and N. Madhwesh, "Thermal performance enhancement of flat plate solar air heater using transverse U-shaped turbulator - A numerical study," J Mech Eng Sci., 2019, vol. 13, no. 3, p. 5562-5587, doi: 10.15282/jmes. 13.3.2019.22.0448.

[58] ANSYS FLUENT 19.2. Documentation, ANSYS, Inc. 